\title{
Are There Schizophrenia Genetic Markers and Mutations? A Systematic Review and Meta-Analyses
}

\author{
Maria Auxiliadora Brasil Sampaio Cardoso1, Tárcia Januário do Nascimento², \\ Gabriel Pereira Bernardo², Lorena Pereira Bernardo², Maria Mirelle Ferreira Leite Barbosa ${ }^{2}$, \\ Pedro Januário Nascimento Neto ${ }^{3}$, Danilo Ferreira de Sousa ${ }^{1}$, Antonio Gilvan Teixeira Júnior ${ }^{3,4}$, \\ Marcos Antonio Pereira de Lima ${ }^{3}$, Marcial Moreno Moreira1, David de Sousa Gregório1, \\ Lídia Coelho do Nascimento Santos' ${ }^{1}$ Modesto Leite Rolim Neto ${ }^{1,2,3}$
}

\author{
${ }^{1}$ Postgraduate Program in Health Science, FMABC, Santo André, Brazil \\ ${ }^{2}$ Faculty of Medicine, Estacio (FMJ), Juazeiro do Norte, Brazil \\ ${ }^{3}$ Federal University of Cariri (UFCA), Faculty of Medicine, Barbalha, Brazil \\ ${ }^{4}$ Science without Borders fellow at University of Liverpool, Liverpool, UK \\ Email: modestorolim@yahoo.com.br
}

How to cite this paper: Cardoso, M.A.B.S., do Nascimento, T.J., Bernardo, G.P., Bernardo, L.P., Barbosa, M.M.F.L., Neto, P.J.N., de Sousa, D.F., Júnior, A.G.T., de Lima, M.A.P., Moreira, M.M., de Sousa Gregório, D., do Nascimento Santos, L.C. and Neto, M.L.R. (2017) Are There Schizophrenia Genetic Markers and Mutations? A Systematic Review and Meta-Analyses. Health, 9, 811-838.

https://doi.org/10.4236/health.2017.95058

Received: November 21, 2016

Accepted: May 19, 2017

Published: May 23, 2017

Copyright (c) 2017 by authors and Scientific Research Publishing Inc. This work is licensed under the Creative Commons Attribution International License (CC BY 4.0).

http://creativecommons.org/licenses/by/4.0/

\begin{abstract}
Background: Schizophrenia is a severe psychiatric disorder with a complex genetic factor determining its disease onset. Nevertheless, it is not clear in this mental disorder. Objective: To conduct a systematic review of articles regarding the genetic markers and mutations in schizophrenia. Methods: A systematic review of articles on genetic markers and mutations in schizophrenia, published from January 1, 2011, to September 7, 2015, on SCOPUS database was carried out. Search terms were "Genetic markers", "Mutation", and "Schizophrenia". Results: Of the 527 retrieved studies, 31 met the eligibility criteria. Genetic polymorphism, Immune-associated genes, TCF4 and ZNF804A association with microRNA, Neuregulin gene, Chromosome 13q32 and 11p15.4, genes involved in glutamatergic via schizophrenia and brain structure, appeared to be associated with the origin of schizophrenia. Conclusion: Some studies show genes involved in several pathways leading to the disease pathogenesis such as that one related with the dopaminergic and immune system, or rare alleles. Some genes present no involvement in the etiology of this mental disorder. These findings clarify the genetic complexity of schizophrenia and affirm that together, the genes have an overall effect greater than the sum of the individual effect of each gene.
\end{abstract}

\section{Keywords}

Schizophrenia, Genetic Markers, Mutations, Systematic Review 


\section{Introduction}

Schizophrenia (MIM 181500) is a complex disease that has a lifetime risk of approximately $1 \%$ and is characterized by delusions, hallucinations, altered cognition, emotional reactivity and disorganized behavior. Genetic factors account for more than $80 \%$ of the variance in susceptibility, and risk likely results from multiple loci of small effect [1] [2]. Supporting evidence has linked the high heritability of schizophrenia (SCZ) to a combination of relatively common alleles of small effect and to a few rare alleles with relatively large effects [3] [4]. Genes like GRIK2, GRIA2, [5] ADAMTSL3 [6] and polymorphism present in the $M A O A$ promoter region was associated with schizophrenia [7]. Due to its complex genetic architecture and joint effects among these genes, the overall effect of a gene network is expected to have a greater effect than the sum of individual effect of each gene [8].

Some of the most investigated genes in studies of susceptibility to schizophrenia are those that encode proteins of the dopaminergic system [4]. The dysfunction of the dopamine system is believed to be a fundamental component in SCZ development [9]. Abnormal transmission of dopamine may be involved in the pathogenesis of SCZ [10] [11] [12]. Beyond that, there is compelling evidence that abnormal brain development and disturbed neuroplasticity are major factors in schizophrenia (SCZ) pathology [1] [2] [3] [13].

Also, was found that the genes involved are mainly neural- and immune-related and more likely to interact and take part in the same or related pathways [8]. The abnormal functioning of the immune system including the irregulation and malfunction of different parameters of immune system are strongly associated with pathogenesis of schizophrenia. There is a strong relationship between the clinical characteristics of schizophrenia and disturbances of the immune system [14] [15]. The major histocompatibility complex (MHC), an immune response gene locus chromosome 6 , is the most extensively associated locus for schizophrenia in genome-wide association study (GWAS) [16] [17] [18]. However, clinical and genetic heterogeneity and overlapping with other neurodevelopmental disorders complicate our understanding of the etiology of schizophrenia [18].

This research was conducted through a systematic review aiming to identify genetic markers and mutations for schizophrenia. Therefore, this work produces a synthesis of the latest findings about the genetic influence in this mental disorder.

\section{Methods}

A meta-analyse and systematic review was performed of articles about genetic markers, mutations, and their relations with schizophrenia.

It was conducted a search in the literature through the online database Scopus, in September 2015, by limiting itself to articles published between January 1, 2011 to September 7, 2015. The reason to limit the search between 2011 and 2015 was because during that period there was a significant improvement in the 
results of research involving genetic mutations and markers for schizophrenia. Therefore, genetic factors involving schizophrenia had great relevance in the scientific community.

Initially, the search terms browsed in Scopus database were:

\#1: "genetic markers" (MeSH term);

\#2: "mutation" (MeSH term); and

\#3: "schizophrenia" (MeSH term).

Analysis of the article followed predetermined eligibility criteria. The survey was carried out in two phases: 1 AND 2 AND 3, 1 AND 3. It was made for those combinations by using the filter "subject descriptor". The index utilized was: Title, Abstract and Keywords. We adopted the following inclusion criteria: 1) written publications in English; 2) studies pertaining schizophrenia and mutations or genetic markers; 3 ) original articles with available full text online; 4) articles that included in the title at least one combination of terms described in the search strategy; and 5) observational (analytical or descriptive, except case reports), experimental or quasi-experimental studies (except animal studies), both prospective and retrospective.

The exclusion criteria were as follows: 1) other study designs, e.g. case reports, case series, literature reviews and comments; 2) non-original studies, including editorials, reviews, forewords, short communications and letters to the editor. Each article was read in its entirety, and the information was entered in a spreadsheet that included authors, year of publication, the study sample description and key data.

Some works found about schizophrenia differed from the proposed theme and were not included because they treat schizophrenia associated with other psychological disorders such as bipolar disorder, by addressing only symptomatic changes or because they are related to disease treatment.

BioEstat 5.0 program was used to calculate the Mantel-Haenszel test and the Odds Ratio (Figure 1) in order to verify the association between the presence of the gene and the chance of developing schizophrenia; the Chi-Square Distribution (Figure 2), which is a probability distribution of the event actually occurs; and the Pearson's correlation coefficient (Figure 3), which represents the degree of association between certain variables.

The following Figure 1 shows the chances ratio of schizophrenia development associated to the genetic factor.

The following Figure 2 represents the probability distribution according to the associated event.

The following Figure 3 represents the Pearson's correlation coefficient, which highlights the genetic markers association with the schizophrenia development according its correlation strength.

To better analyze the data, the following stage involved the comparison between the articles and the division of the results obtained from the Reading of each one of them in eight categories: GENETIC POLYMORPHISM ( $A N N E X I N$ A5, THBS1, PDLIM5, HDAC, DISC 1 gene, KCN/3, RGS2, MAOA gene, 


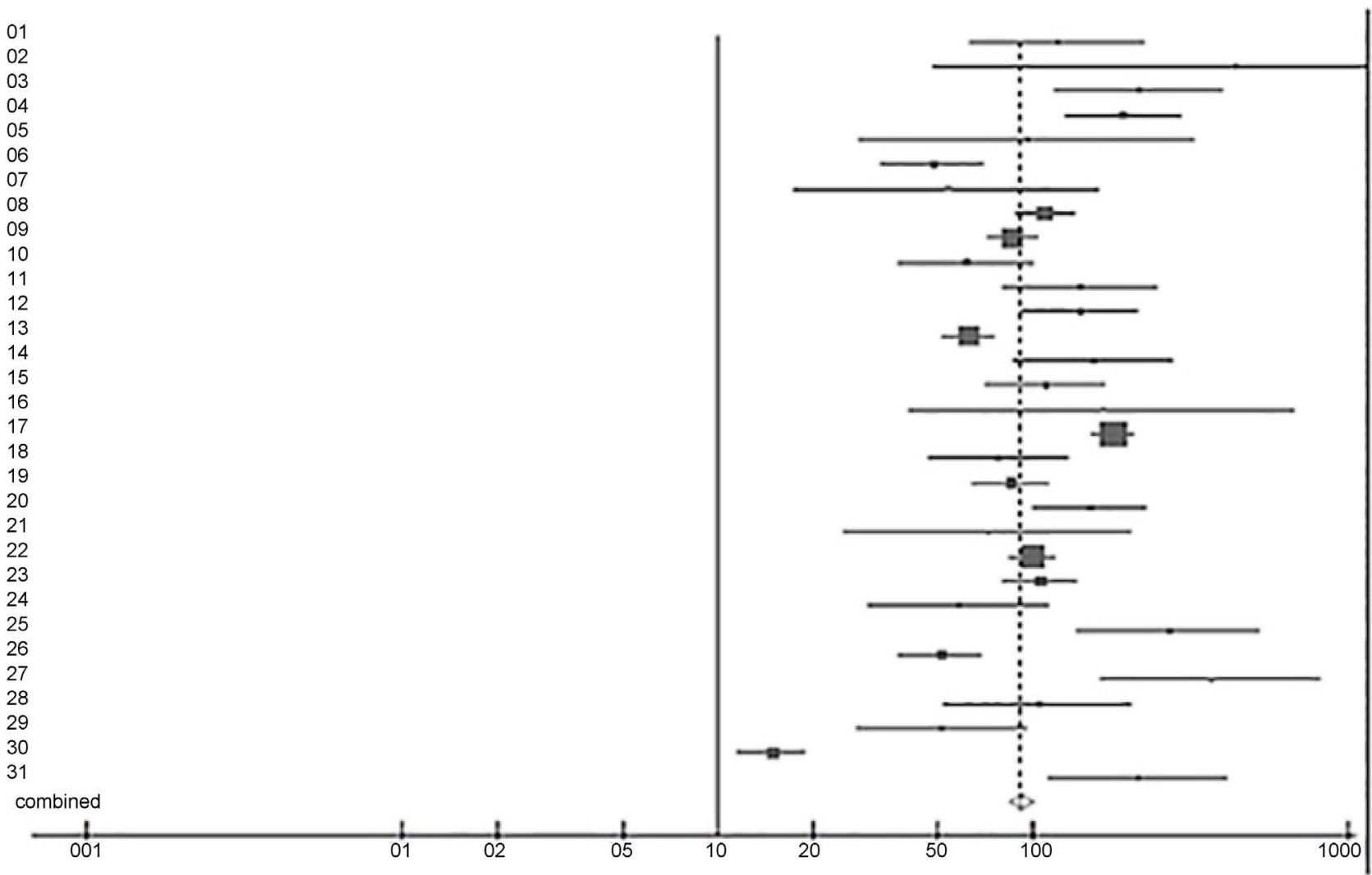

Figure 1. Mantel-Haenszel test and odds ratio. Prepared by the authors. The Mantel-Haenszel test and the odds ratio were used in order to calculate the genetic association and the disease establishment. Each set of studies is represented by a line and a square. The former represents the confidence interval and the latter the studies' effect. The square size represents the importance of each set of studies to the meta-analyses. The vertical line shows the effect absence while the diamond symbolizes the final meta-analysis result. The joint analysis involving all study patients had odds ratio 9.07 CI [8.540 - 9.64]. This means that if someone has a genetic load compatible with schizophrenia, the chance of developing this disease is 9 times higher.

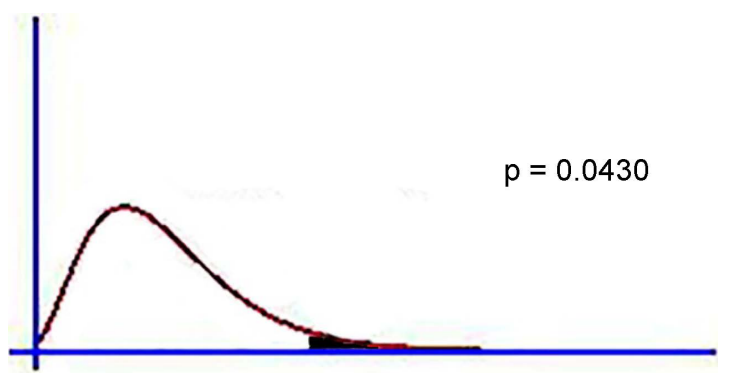

Figure 2. Chi-square distribution, prepared by the authors. The chi-square distribution was used in order to calculate the probability distribution of the event actually occurs. This involves the freedom degree and it is based on the odds ratio and on the chi-square calculated together and also according to the odds ratio set. With the $\mathrm{p}=0.0430$, the hypothesis of genetic association on the schizophrenia onset is not rejected.

$A N K K 1, D R D 3, G R I K 1$ ); IMMUNE-ASSOCIATED GENES (NKAPL, PGBD1, RELA), TCF4 and ZNF804A; ASSOCIATION WITH MICRORNA; NEUREGULIN GENE (NRG1, ERBB4); CHROMOSSOME 13q32 and 11p15.4; GENES INVOLVED IN GLUTAMATERGIC VIA (PTPN5 gene, GRIN2B, GRIK1, GRIK2, GRIA2, DTNBP1 gene, FXYD6); SCHIZOPHRENIA AND 
BRAIN STRUCTURE (B3GAT2, ADAMTSL3, DTNBP1 gene); and finally, NEGATIVE RESULTS (PEA15, ENTPD4, GAS2L1, ZIC2, SLC15A1, and FGF14).

\section{Results}

At first, the aforementioned search strategies resulted in 527 references. After searching the title and abstract of the considered citations for eligibility based on study inclusion criteria, 496 articles were excluded and 31 articles were further retrieved and included in the final sample (Figure 4).

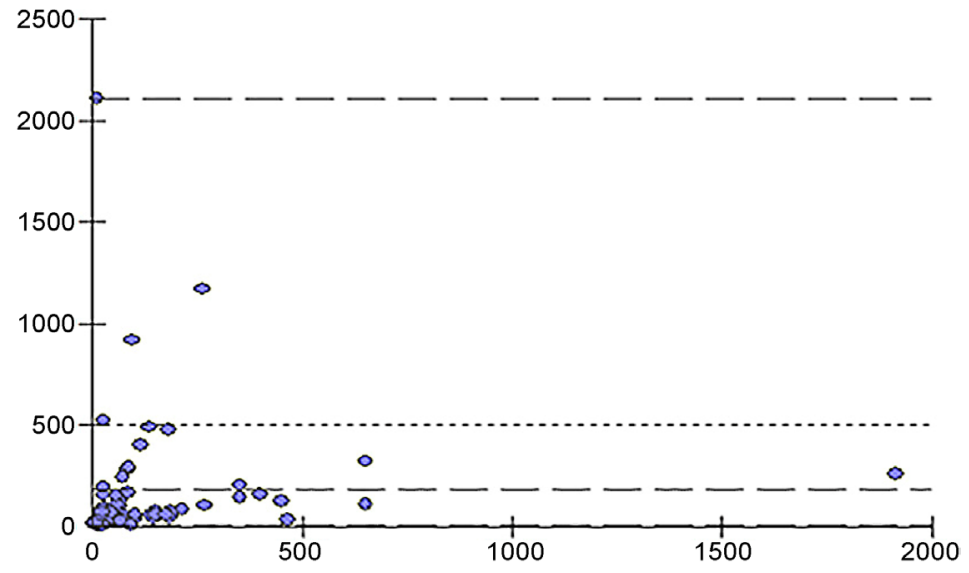

Figure 3. Person's correlation coefficient, prepared by the authors. The Pearson correlation was used in order to verify the statistical relationship between the genetic variable and the schizophrenia onset. It is a parameter ranging from -1 to 1 , in which -1 means a total negative correlation, 0 means no correlation and means 1 overall positive correlation. According to the analysis from the studies, we found a correlation outcome $r=0.79$, which shows quantitatively that the schizophrenia development is associated with a genetic marker.

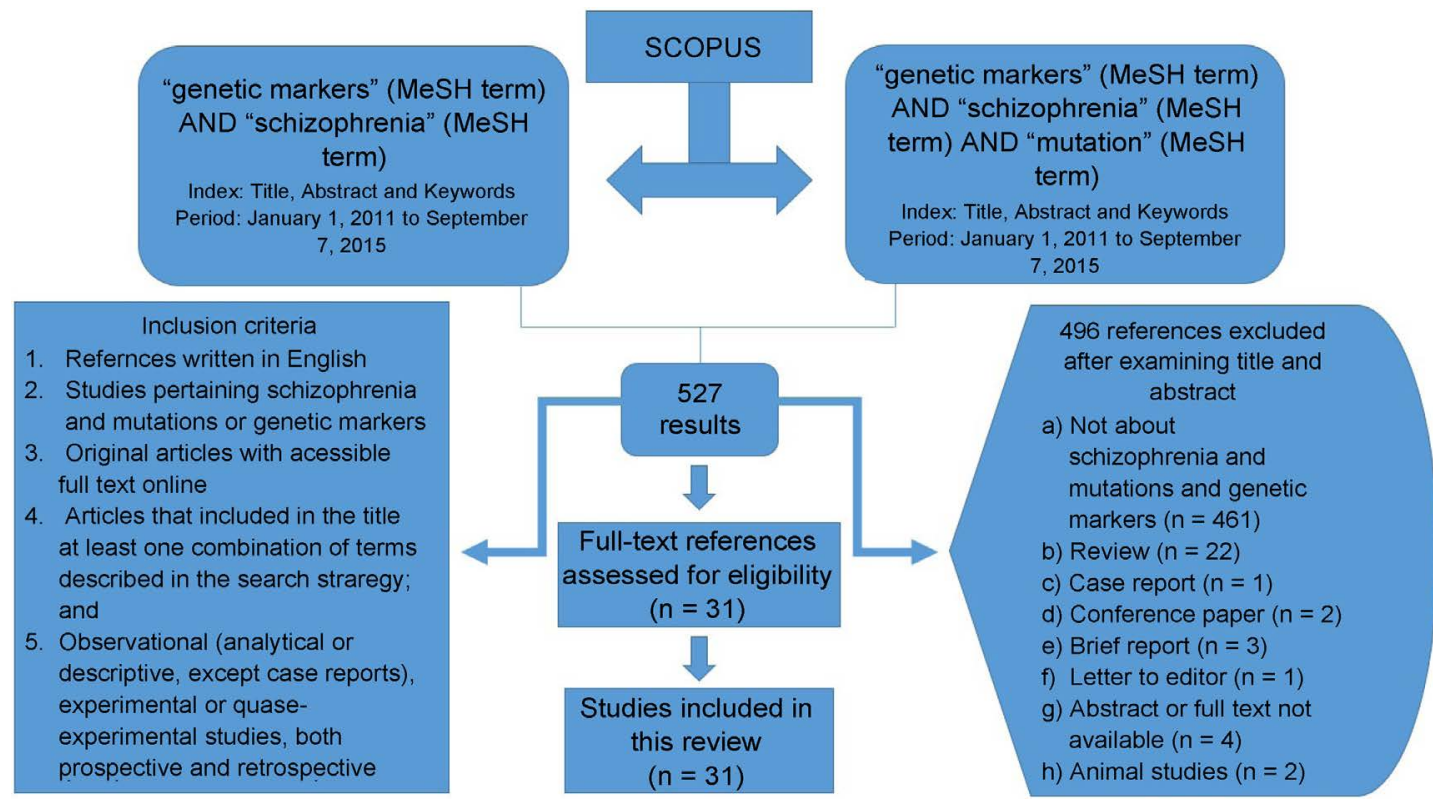

Figure 4. Flow chart showing study selection for the review. Abbreviations: MeSH: Medical Subject Headings. 
Articles from SCOPUS database matched the inclusion criteria of the present study. The 31 studies were distributed into the previously determined eight categories as follows: Genetic polymorphism: Boyajyan et al., 2013, Park et al., 2012, Moselhy et al., 2015, Kebir et al., 2014, Cao et al., 2013, Yamada et al., 2012, Gareeva et al., 2013, Sun et al., 2012, Arab et al., 2015, Dai et al., 2014, Norlelawati et al. 2015, (eleven studies), Immune-associated genes, Hashimoto et al., 2012, Zhang et al., 2013, Yu et al., 2014, (three studies), TCF4 and ZNF804A association with microRNA, Zhang et al., 2012, Cattane et al., 2015, (two studies), Neuregulin gene, Naz et al., 2011, ChuanYuan et al., 2011, Ryu et al., 2013, Joshi et al., 2014 (four studies), Chromossome 13q32 and 11p15.4, Gadelha et al., 2012, (one study), Genes involved in glutamatergic via, Gareeva et al., 2013, Pelov et al., 2012, Gareeva et al., 2014, Hirata et al., 2012, Cerasa al, 2012, Zhong et al., 2011, (six studies), Schizophrenia and brain structure, Kähler et al., 2011, Dow et al., 2011, Cerasa et al., 2012, (three studies), Negative results, Saito et al., 2011, Zhang et al., 2012, Gadelha et al., 2012, (three studies). Among the 31 studies, some works were referenced in more than one category. The categorization of studies aims to a better organizational quality systematic review and it is not compulsory that each article must be referenced only in their respective category. Table 1 provides an overview of all studies included in the final sample and of all data elements used during the data analysis process.

\section{Discussion}

Schizophrenia is a heterogeneous and complex disorder, the etiology of which remains unknown [19]. However, it is considered a complex trait resulting from both genetic and shared environmental etiological influences as reviewed by Sullivan [20]. The genetic contribution to risk is high and heritability estimates based on clinical ascertainment are usually given as over $80 \%$ [21] [22] [23] (Figure 5).

\subsection{Genetic Polymorphism}

\subsubsection{Annexin A5 and Apoptotic Processes}

It is proposed that both pre and postnatal as well as genetically determined abnormalities of the apoptotic processes might be among factors responsible for the development of schizophrenia [24].

It was shown that annexin A5 coupled to membrane of apoptotic cells is a ligand for C1q protein [25].

The increased levels of annexin A5 and Hficolin in the blood of schizophrenia patients might result from the intensification of the processes of programmed death of cells in the central blood circulation or/and might reflect alterations at the level of neuronal apoptosis due to increase of the bloodbrain barrier permeability in this disorder [26].

The results on genotyping the rs 1157945 polymorphism of the annexin A5 gene definitely suggest the association between this mutation and schizophrenia, which enable one to consider the rs $1157945^{*} \mathrm{~T}$ minor allele of the annexin A5 gene to be a risk factor for disease development [27]. 
Table 1. Are there schizophrenia genetic markers and mutation? Studies and main findings.

\begin{tabular}{lll}
\hline $\begin{array}{l}\text { Authors and } \\
\text { Year }\end{array}$ & Sample & Main findings \\
\hline
\end{tabular}

Results confirmed previous findings from different ethnic populations, in that the rs 1800497 and rs909253 polymorphisms were both associated with risk of schizophrenia. Differences between the genotypes of cases and controls were strongly significant $(P=0.0005$

Arab et al. (2015) [4]

120 patients with DSM-IV and PANSS (Positive and Negative Syndrome Scale) assessments of schizophrenia and 100 healthy controls.

for rs 1800497 and $P=0.001$ for rs909253). The relative risk to schizophrenia was $1.2(P=0.01)$ for the $\mathrm{C}$ allele and $0.8(P=0.04)$ for the $\mathrm{G}$ allele. The CC, GG, and combined CC/AA genotypes were all more frequent in cases than in controls. These results support an

association between $A N K K 1$ and $L T A$ genetic markers and vulnerability to schizophrenia and show the potential influence of just one copy of the mutant $\mathrm{C}$ or $\mathrm{G}$ allele in the Egyptian population.

This study reports the upregulation of JUN, HIST2H2BE, FOSB, $F O S, E G R 1$ and TCF4 in the fibroblasts of SCZ patients. A significant alteration in $E G R 1$ expression is also present in SCZ PBCs compared to controls and to MDD and BD patients, suggesting that this gene could be a specific biomarker helpful in the differential diagnosis of major psychoses.

It was found a secondary association between PDLIM5 variants and the paranoid subtype of schizophrenia in Emirati Arabs suggesting

Moselhy et al. (2015)

121 patients with schizophrenia (SCZ) and 170 controls were genotyped using quality controlled primers.

Norlelawati 225 unrelated schizophrenia patients and 350 healthy controls. et al. (2015) Schizophrenia cases were collected from the Psychiatry Clinic [46] of Tengku Ampuan Afzan Hospital, Kuantan (HTAA).

A total of 30 paranoid ( 15 males and 15 females) and 29 undifferentiated (15 males and 14 females) SCZ patients were

Dai et al. collected as cases from Ningbo Kangning Hospital. In addition, (2014) [11] 26 age- and gender-matched volunteers in Ningbo Kangning Hospital were enrolled as healthy controls (12 males and 15 females).

A test sample included 257 patients diagnosed with PSZ F.20.0xx according to the 10th revision of the International Classification of Diseases (ICD10), of which 108 (49 females

Gareeva et al.and 59 males) were Russians and 149 (71 females and 78 males) (2014) [5] were Tatars. The patients were treated at Republican Mental Hospital no. 1 (Ufa). The mean age was $24.94 \pm 8.91$ years; the mean age at disease onset, $22.46 \pm 7.32$ years; and the mean disease history, $3.69 \pm 3.85$ years.

Postmortem frozen tissues from 30 schizophrenia cases, 7 Joshi et al. schizoaffective cases, and 37 well-matched control individuals (2014) [40] were provided by the New South Wales Tissue Resource Centre (TRC cohort).

Families were included in this study based on the presence of Kebir et al. one proband diagnosed with schizophrenia or schizoaffective (2014) [41] disorder. The global sample included 951 Caucasian subjects in 313 nuclear families ( 325 cases and their 626 parents forming that PDLIM5 may represent a determinate/marker for schizophrenia subtype specification. However, no associations were found with variants in PICK1, NRG3 or DISC1 genes.

The study supports the notion that the DISC1 gene is a marker of schizophrenia susceptibility and that rs2509382 in the mutual DISC1 translocation region is a susceptibility marker for schizophrenia among males in Malaysia.

Their findings supported that $D R D 3$ gene body hypermethylation was significantly associated with the risk of SCZ.

The findings support the hypothesis that glutamate receptor genes are involved in the etiology and pathogenesis of schizophrenia.

Their findings demonstrate that ErbB4-pan laminar mRNA expression is elevated (layers I, II, V) in schizophrenia. At the cellular level, ErbB4-pan mRNA+ signal was detected predominantly in interneuron-like neurons. They provide evidence from this independent Australian postmortem cohort that ErbB4-JMa expression is elevated in schizophrenia and is linked to deficits in dendrite-targeting somatostatin, neuropeptide $\mathrm{Y}$ and vasoactive intestinal peptide interneurons.

This first exploratory systematic study of the $H D A C$ genes provides consistent support for the involvement of the HDAC3 gene in the etiology of schizophrenia. A statistical epistatic interaction between 


\section{Continued}

325 case-parent trios). It was composed of four samples: 1) The REFAPSY cohort: 274 subjects in 88 nuclear families ( 98 cases and 176 parents forming 98 case-parent trios) (multi-center enrollment, France), 2) The "Colombes" cohort: 182 subjects in 60 nuclear families (62 cases and 120 parents forming 62

Yu et al.

(2014) [8] case-parent trios) (Paris, France), 3) The "Barcelona" cohort: 411 subjects in 137 nuclear families (137 cases and 274 parents forming 137 case-parent trios) (multi-center enrollment, Spain), and 4) The "Montreal" cohort: 84 subjects in 28 nuclear families ( 28 cases and 56 founders. forming 28 case-parent trios) (Montreal, Canada).
GWAS samples (768 schizophrenia cases and 1733 normal controls) came from individuals of Han Chinese ancestry, genotyped with Illumina Human610-Quad BeadChips.
Gareeva et al. (2013)

56 families with 183 members including 123 affected individuals in the QTL linkage scan and 80 men) undergoing treatment in the Republican Republic Bashkortostan participated in the study.
Cao et al. The case samples were 310 random unrelated schizophrenia (2013) [45] patients (144 male and 166 female)

Zhang et al. 902 cases and 1091 healthy controls in an attempt to replicate (2013) [62] the GWAS results in the Chinese Han population
$H D A C 9, H D A C 10$, and $H D A C 11$ was detected and seems biologically plausible.

As a result, it was identified one gene set with a joint effect significantly associated with schizophrenia and gene expression profiling analysis suggested that they were mainly neuro- and immune-related genes, such as glutamatergic gene (GRM5), GABAergic genes (GABRB1, GABARAP) and genes located in the MHC region ( $H L A-C$, TAP2, HIST1H1B). Further pathway enrichment analysis suggested that these genes are involved in processes related to neuronal and immune systems, such as the Adherens junction pathway, the Neurotrophin signaling pathway and the Toll-like receptor signaling pathway.

A group of 258 patients diagnosed with paranoid schizophrenia F20.0xx (according to the international classification of diseases ICD10, paranoid schizophrenia in subjects of different ethnic backgrounds) including 110 Russians (50 women and 60 men) and 148 Tatars (68 women Psychiatric Hospital No. 1 of the Ministry of Health of the

The examined subjects are represented by 251 patients with paranoid schizophre nia F.20.0xx in accordance with the International Classification of Diseases ICD10 of PS with
The results are consistent with those obtained previously and support the hypothesis concerning the association of RGS2 gene polymorphisms with the risk of extrapyramidal syndrome development during haloperidol therapy and their involvement in the etiology and pathogenesis of schizophrenia.

Was observed seven regions yielding linkage signals attaining genome-wide empirical thresholds for suggestive linkage (NPL $Z$ score $=2.78$ - 3.49); chromosome 15q26.1 for "non-paranoid delusion factor", 2 p24.3 and 7q31.1 for "prodromal impairment factor", 1q32.1, $9 \mathrm{p} 21.3$, and 9q31.2 for "negative symptom factor", and 10p13 for "disorganization factor". Among these loci, chromosome 2p24.3 and 1q32.1 overlap with susceptibility loci of schizophrenia identified in our previous linkage studies. This study suggests the existence of genetic loci related to various clinical features of schizophrenia. warranted.

Their results provide further evidence for an effect of the DISC1 gene on the etiology of schizophrenia and suggest that STRs in the DISC1 gene may be genetic risk factors for schizophrenia.

Locus 6p21-p22.1 is significantly associated with schizophrenia in the Chinese Han population. To further investigate the association between polymorphisms at this locus and schizophrenia. Was selected eight other single-nucleotide polymorphisms (SNPs) distributed in or near these genes for a case-control association study in an independent.

In the course of the analysis, this study revealed the following: 1) genetic markers of increased risk of developing paranoid schizophrenia in various ethnic groups, including, in Tatars, the $\operatorname{GRIN2} B^{\star} T 1{ }^{\star} T$ genotype $(\mathrm{p}=0.003 ; \mathrm{OR}=2.33)$ and $G R I N 2 B^{*} T$ allele $(\mathrm{p}=0.001 ; \mathrm{OR}=$ 2.36), rs1805247; in Russians, the GRIN2B ${ }^{\star} T{ }^{*} T$ Further genetic analyses for these dimensional phenotypes are 
Gareeva different ethnicities, including 108 Russians (48 women and 60 et al. (2013) men) and 143 Tatars (67 women and 76 men), which were [94] treated in RPH no. 1 at Ufa city.

Study subjects were patients with the paranoid form of schizophrenia diagnosed by psychiatrists at the Psychiatric Medical Center of the Ministry of Health of the Republic of Boyajyan Armenia based on the criteria of the International Classification et al. (2013) of Diseases (ICD10 code: F20.0). In total, 225 chronic patients

[27] treated with typical neuroleptic haloperidol, 25 firstepisode neurolepticfree patients, and 225 healthy subjects (control group) were investigated. In the group of chronic patients 154 males and 71 females were enrolled.

Gadelha

et al. (2012)

[23]

Zhang et al.

(2012) [12]

768 patients and 1348 controls. A second sample used 963 patients and 992 controls in the Han Chinese population.

Hirata et al. (2012) [104]

202 unrelated patients with a DSM-III-R or DSM-IV diagnosis of schizophrenia, as well as for the schizophrenia probands of 108 small nuclear families. Case-control sample and family based sample are completely independent. Each schizophrenia case was matched with a healthy control $(\mathrm{N}=211)$ on the basis of age, ethnicity, and sex. There were 128 male and 74 female cases. In the case-control study, the Caucasian-only sample was 169 of 202 cases $(83.7 \%)$. In the family-based study, the Caucasian subset was 73 of 108 probands (67.5\%).

Zhang et al. Han Chinese sample comprised of 492 schizophrenia patients (2012) [71] and 516 healthy control subjects.

Park et al.

Two hundred and twenty Korean schizophrenia patients (mean (2012) age \pm standard deviation, $42.1 \pm 10.6$ years; male/female $=$ $123 / 97)$ and 376 control subjects ( $44.3 \pm 6.3$ years; male/female $=192 / 184)$ were enrolled for this study.

Brain samples were taken from 35 schizophrenics (26 males, 9 females; mean \pm SD age, $42.6 \pm 8.5$ years; postmortem interval Yamada (PMI), $31.4 \pm 15.5 \mathrm{~h}$; brain $\mathrm{pH}, 6.5 \pm 0.2$ ), 35 bipolar disorder et al. (2012) patients (17 males, 18 females; mean \pm SD age, $45.3 \pm 10.5$

[47] years; PMI, $37.9 \pm 18.3 \mathrm{~h}$; brain $\mathrm{pH}, 6.4 \pm 0.3$ ), and 35 controls

(26 males, 9 females; mean \pm SD age, $44.2 \pm 7.6$ years; PMI, $29.4 \pm 12.9$ h; brain $\mathrm{pH}, 6.6 \pm 0.3)$.

1224 patients with schizophrenia (50.9\% male (623/601), mean age \pm SD: $46.2 \pm 15.0$ years) and 1663 healthy controls genotype $(\mathrm{p}=0.038$; $\mathrm{OR}=2.12)$ and $G R I N 2 B^{*} T$ allele $(\mathrm{p}=0.028$; $\mathrm{OR}=2.03)$, rs 1805247 , genotype $G R I N 2 B^{*} A /{ }^{*} A(\mathrm{p}=0.042$; $\mathrm{OR}=$

2.12), rs1805476; 2) genetic markers of the reduced risk of developing paranoid schizophrenia; 3 ) genetic markers of therapy response and the risk of side effects development during neuroleptics (haloperidol) treatment in Bashkortostan.

It was shown that the pathogenesis of schizophrenia is characterized by an increased rate of apoptosis, which is more pronounced in the case of the first-episode neuroleptic-free patients than in the case of chronic patients that receive typical neuroleptic haloperidol. It was also shown that the rs 11575945 polymorphism of the annexin A5 gene is associated with schizophrenia, and its minor allele is responsible for higher levels of the annexin A5 protein in the blood and represents one of the risk factors for the development of this disease.

$13 q 32$ has been reported to be linked to schizophrenia by multiple different studies. Thus, this study provides additional supporting evidence for an aetiological role of variants at $13 \mathrm{q} 32$ in schizophrenia.

Association analysis of nine SNPs failed to detect any positive markers or haplotypes. Then, was tested rs4680 in a validation and no significant association was observed, but the cases significantly deviated from Hardy-Weinberg equilibrium $(\mathrm{p}=5.7 \mathrm{e}-4)$. There was no association of rs 4680 with SZ in the combined sample ( $\mathrm{n}=4071$, $\mathrm{p}=0.110$, odds ratio $=1.08$ ).

Was analyzed eight SNPs across the GRIK1 gene. The marker rs469472 was associated with schizophrenia when we combined the case-control and family samples $(\mathrm{p}=0.027)$.

Was found association between $Z N F 84 A$ and schizophrenia. $Z N F 804 A$ single nucleotide polymorphisms (SNPs) encompassing exon 4 by performing an association study. In addition, was observed a significant association between marker rsl344706 and schizophrenia $\left(\mathrm{P}<1.0 \times 10^{-5}\right)$ in combined populations.

We genotyped two cSNPs [rs2228261 (Asn470Asn) and rs2292305 (Thr523Ala)] using direct sequencing. In this study, rs2228261

revealed significant association with schizophrenia in both codom-inant and recessive models. Also, rs2292305 was associated with schizophrenia in the recessive model. The results suggest that the THBS1 gene may contribute to the susceptibility of schizophrenia.

In the study, a single nucleotide polymorphism (SNP) (rs3106653) in the $K C N J 3$ (potassium inwardly rectifying channel, subfamily J,

member 3) gene located at 2q24.1 showed association with schizophrenia. KCNJ3, also termed GIRK1 or Kir3.1, is a member of the $\mathrm{G}$ protein activated inwardly rectifying $\mathrm{K}+$ channel (GIRK) group.

It was genotyped four single-nucleotide polymorphisms (SNPs) in the RELA gene and performed a gene-based association analysis. 


\section{Continued}

$\begin{array}{lc}\text { Hashimoto } & (46.5 \% \text { male }(773 / 890), \text { mean age } \pm \text { SD: } 46.9 \pm 20.7 \\ \text { et al. }(2011) & \text { years }) .\end{array}$

[70]

576 individuals diagnosed with schizophrenia (290 males, mean age $=35.3 \pm 11.6 ; 286$ females, mean age $=32.7 \pm 13.4)$ and 566 healthy control subjects

Zhong et al. (2011) [2]

Naz et al.

(2011) [15]

Schizophrenia patients and in controls. One hundred patients with schizophrenia and 70 healthy controls participated in the present study.

ChuanYuan et al. (2011)

Pelov et al.

(2011) [98]

Dow et al. (2011) [6]

hole blood samples were randomly selected from 92 schizophrenia patients from both the Munich and Aberdeen subjects.

One hundred and seven healthy individuals

Cerasa et al. (2011) [102]

868 Israeli Jewish participants, of whom 286 were patients with SZ and 582 were healthy controls. SZ patients were included with information regarding ethnicity (Ashkenazi vs. non-Ashkenazi origin).

(Caucasian, age-range: 18 - 73) recruited from universities, community recreational centers and hospital personnel from 2005 to 2009.

Saito et al. Subset of subjects (94 schizophrenia patients and 94 (2011) [120] control subjects).

Sun et al. (2011) [7]

555 unrelated patients with paranoid schizophrenia and 567 unrelated healthy controls. A second sample analyzed 73 drug-free patients.

Kähler et al. Norwegian subset (98 cases; 177 control subjects) with (2011) [13] structural magnetic resonance imaging data.

Was found significant associations of three SNPs (rs11820062: p0.00011, rs2306365: p0.0031, and rs7119750: p0.0080) with schizophrenia and stronger evidence for association in a multi-marker sliding window haplotype analysis (the lowest p0.00006).

It was genotyped six single-nucleotide polymorphisms (SNPs) in this region of FXYD6 in 1142 Han Chinese subjects (576 cases and 566 controls), and performed an association analysis. Significant associations with schizophrenia and the marker rs11544201 $(\mathrm{P}=0.0028)$ and the haplotype rs10790212-rs11544201 (global $\mathrm{P}=0.005$ ) were found.

It was examined the association between the neuregulin 1 and tumor necrosis factor- $\alpha(-308)$ gene polymorphism with schizophrenia. This association was performed on the basis of molecular biology to screen the mutations of neuregulin 1 and tumor necrosis factor- $\alpha(-308)$ gene in schizophrenic patients by polymorphism analysis. Statistical analysis of the observed data shows that there was an association $(\mathrm{P}=0.003)$ between patient's group and controls in terms of genotypes of single-nucleotide polymorphism 1 rather than single-nucleotide polymorphism 2 of neuregulin 1.

The authors found that genetic variants of the FZD3 gene may affect susceptibility to schizophrenia in Chinese Han and Va populations.

The results imply a model in which PTPN5 may play a role in normal cognitive functioning and contribute to aspects of the neuropathology of SZ.

Imputation analysis refined association between $A D A M T S L 3$ and schizophrenia, and highlighted additional common variants with similar levels of association. We evaluated the functional consequences of all variants identified by sequencing, or showing direct or imputed association. The strongest evidence for function remained with the originally associated variant, rs950169, suggesting that this variant may be causal of the association. Rare variants were also identified with possible functional impact.

Surface-based analysis of the cortical mantle showed that the dysbindin haplotype was associated with structural differences in the medial orbitofrontal cortex, where the risk carriers showed the highest cortical thickness values and the non-risk carriers the lowest. This study extends previous evidence found on schizophrenic patients to the healthy population, demonstrating the influence of dysbindin risk variants on the neuronal architecture of a specific brain region relevant to the neuropathology of schizophrenia.

The study fails to provide evidence for the contribution of PEA15, ENTPD4, and $G A S 2 L 1$ genes to the etiology of schizophrenia in the Japanese population.

Haplotypic association was found for the VNTR-rs6323, VNTR rs1137070, and VNTRrs6323-rs1137070 haplotypes in female subjects. Nevertheless, no significant change of the expression of MAOA mRNA was detected in either female or male patients with paranoid schizophrenia.

The present results suggest that effects on biosynthesis of the neuronal epitope HNK-1, through common B3GAT2 variation, could increase the risk of SCZ, possibly by decreasing cortical area. 


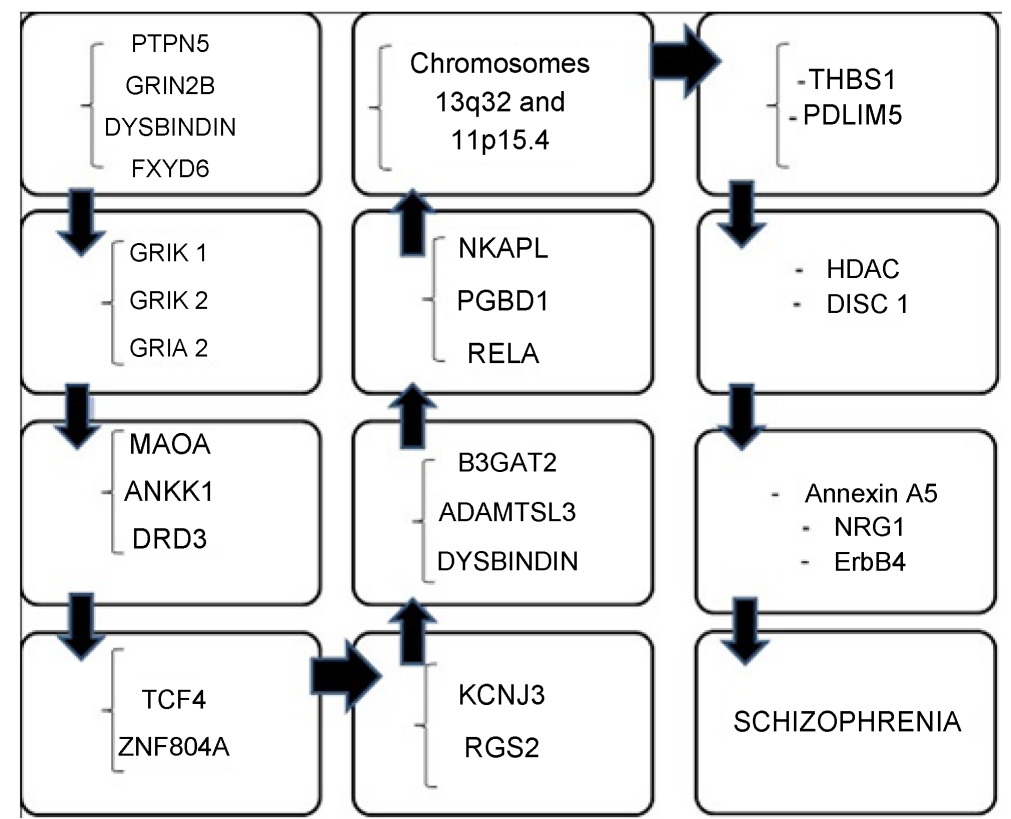

Figure 5. Genes that influence the susceptibility of schizophrenia.

\subsubsection{Synaptic Regulation and Schizophrenia}

Recently, thrombospondin 1 (THBS1) was discovered to be the essential astrocyte-derived synaptogenesis-promoting factor, and has been shown to contribute to the repair of brain injury through its assistance and promotion of neurogenesis [28] [29] [30].

Another work reported a gene PDLIM5 that is localized to the postsynaptic density where it has an important role in limiting the size of dendritic spines-the small synaptic protrusions that serve as the primary sites of excitatory synaptic transmission in the CNS [31] [32].

THBS1 is a $16.39 \mathrm{~kb}$ gene located on chromosome $15 \mathrm{q} 15$. The chromosome $15 \mathrm{q} 15$ region has been reported to be a susceptibility locus on schizophrenia [33] [34] [35], and clinical symptoms of schizophrenia such as periodic catatonia [33] [34].

PDLIM5 was found to be a significant secondary predictor of the paranoid subtype of schizophrenia in this Emirati Arab cohort [18].

Little is known about the biological function of THBS1 in the brain or in schizophrenia. However, given the involvement of astrocytes in the pathogenesis of schizophrenia, and the role of THBS1 in synaptic alteration, it is speculated that THBS1 may be a candidate gene involved in schizophrenia [33] [34] [35].

The finding here of PDLIM5 as a potential marker of schizophrenia subtype expands the role of synaptogenesis in neuropsychiatric disorders more generally [36] [37].

\subsubsection{HDAC (Histone Deacetylases)}

Several studies suggest the involvement of $H D A C$ dysfunction in major psychotic disorders. First, mRNA expression levels of GAD67 in the prefrontal cortex of patients with schizophrenia were found to be strongly and negatively cor- 
related with mRNA expression levels of $H D A C s$ 1, 3, and 4 [38]. In the same way, a common variant in $H D A C 3$ region and epistatic interactions between $H D A C$, $H D A C 10$ and $H D A C 11$ genes were found associated with schizophrenia. Second, $H D A C$ activity has been found to be enhanced in the prefrontal cortex of patients with schizophrenia [39].

Given that $H D A C$ proteins interact and form multiprotein complexes [40], and that a $H D A C$ protein seldom operates alone, was tested that epistatic interaction between polymorphisms of $H D A C$ genes may confer an increased risk of schizophrenia [41].

\subsubsection{DISC1 Gene}

Mutant DISC1 is proposed to contribute to schizophrenia susceptibility by disrupting intracellular transport, neurite modeling, neuronal migration, and proper development of the cerebral cortex [42] [43] [44]. A study found three highly polymorphic STR loci in introns 1,8 , and 9 of the DISC1 gene and identified two novel loci, including (ATCC)n1 and (ATCC)n2. The three STRs showed a significant association with schizophrenia. It is noteworthy that the allele distribution of D1S1621 showed a higher risk of schizophrenia [45].

Another study found two SNPs (rs4658971 and rs1538979) to be significantly associated with schizophrenia in terms of both genotypes and allelic distribution. Additionally, it was found an association of rs2509382 with schizophrenia among male participants [46].

\subsubsection{Gene Association Involved with G-Protein and Schizophrenia} In the research of Yamada et al. [47], a gene found is the $K C N J 3$, also known as GIRK1/KIR3.1. This gene is a novel candidate gene for schizophrenia. The gene encodes a G protein-activated inwardly rectifying potassium channel (GIRK1/KIR3.1) and belongs KIR3.X the subfamily of potassium rectification inside channels. In that study, a single nucleotide polymorphism (SNP) (rs3106653) in the $K C N / 3$ (potassium inwardly rectifying channel, subfamily J, member 3) gene located at 2q24.1 showed association with schizophrenia in two independent sample sets. Moreover, experiments real-time quantitative RT-PCR showed that $K C N J 3$ is regulated in the prefrontal cortex schizophrenic patients. Decreased gene expression was observed in the brains from bipolar disorder, as well as schizophrenia patients. This finding may lend support to the "hypo-NMDA theory of schizophrenia" [47].

In this way, any research groups are investigating the gene family of regulators of G-protein signaling (RGSs) because these genes modulate signal transduction via multiple neurotransmitter receptors (i.e., dopamine, glutamate, serotonin, and $\gamma$-aminobutyric acid) involved in the pathogenesis of schizophrenia [48] [49] [50] [51] [52].

Associations between several polymorphisms of the RGS2 gene and the severity of schizophrenia were identified in patients by data show that the $R G S 2^{\star} G^{\star} G^{\star} T^{\star} C^{\star} T$ haplotype for the rs2746071, rs2746072, rs2746073, rs4606, and rs3767488 polymorphisms of the RGS2 gene is a genetic marker of increased 
risk of schizophrenia in Russian and Tatar residents of the Republic of Bashkortostan. Furthermore, the $R G S 2{ }^{*} G /{ }^{*} G$ genotype and the $R G S 2{ }^{\star} G$ allele of the polymorphic rs2746071 locus of the $R G S 2$ gene are risk factors for the development of schizophrenia in Russians and Tatars. The $R G S 2{ }^{*} A /{ }^{*} A$ genotype, the $R G S 2{ }^{*} A$ allele of the polymorphic rs2746071 locus of the RGS2 gene, and the $R G S{ }^{*} A^{*} G^{*} T^{*} C^{\star} T$ haplotype (rs2746071, rs2746072, rs2746073, rs4606, and rs3767488) of the RGS2 gene are protective with regard to the risk of developing paranoid schizophrenia in Russians and Tatars [52].

The conclusion from their study is consistent with results obtained previously, and supports the hypothesis concerning the association of polymorphisms RGS2 gene involvement in the etiology and pathogenesis of schizophrenia [52].

\subsubsection{Dopamine Association with Schizophrenia}

Dopamine neurons in the substantia nigra are key neurotransmitters in human brain that contribute to the pathogenesis of SCZ [53].

The "dopamine-serotonin" imbalance hypothesis of schizophrenia claims that disruption in cortical-subcortical dopamine and serotonin neurotransmission may play an important role in the pathogenesis of schizophrenia [7] [54].

Monoamine oxidase A (MAOA) is the enzyme responsible for degradation of several monoamines, such as dopamine and serotonin that are considered as being two of the most important neurotransmitters involved in the pathophysiology of schizophrenia [7]. In a study of Chinese population, all the informative SNPs and the VNTR polymorphism within the MAOA gene were screened. The present results suggest that haplotypes $\operatorname{VNTR}(\mathrm{L})$-rs6323(T), VNTR(L)rs1137070(C), and VNTR-(L)-rs6323(T)-rs1137070(C) may be associated with the increased risk of paranoid schizophrenia in female subjects [7]. Other genes also investigated in susceptibility studies schizophrenia are those encoding proteins the dopaminergic system [4].

One such gene is the rs1800497 single nucleotide polymorphism (SNP) It was identified in exon 8 of repetition and Ankyrin kinase domain containing 1 gene (ANKK1) (MIM 608774) only $10 \mathrm{~kb}$ away from D2 (DRD2) dopamine receptor gene (located on 11q23.2, MIM 126450) in the 3'untranslated region. This polymorphism which leads to a substitution glutamic acid to lysine base (E713K) that can high-specificity substrate binding [55] probably modulates the function and expression of $D R D 2$ due to its proximity [56]. Despite the fact that the SNP rs1800497 is located $A N K K 1$ the gene appears to be in linkage disequilibrium with several genetic variants $D R D 2$, which could potentially explain a dopaminergic role in the pathogenesis of schizophrenia [4] [57].

Dai et al. [11] demonstrated that the $D R D 3$ gene methylation, subtype of the dopamine receptor family, may have the potential to serve as a gender-specific biomarker to monitor the risk and development of schizophrenia.

\subsection{Immune-Associated Genes}

In recent years, the extended MHC region has been implicated as a main factor in schizophrenia pathogenesis, supported by GWASs of schizophrenia in differ- 
ent populations [16] [58] [59] [60] [61] [62]. Products of the MHC region implicated in the pathogenesis of schizophrenia not only contribute to immune responses but also have general functions in different molecular biological processes [62] [63]. Numerous other genes in the extended MHC region have been shown to be involved in the pathogenesis of schizophrenia. MICB, HLA-A, and HLA-B are classic MHC molecules that play central roles in the development of host defense and immunity [62] [64] [65].

In fact, more and more evidence suggested immune-related genes may play important roles in schizophrenia [8]. For example, several GWAS revealed that many immune genes are significantly associated with schizophrenia [8] [59] [66] [67]. In a replication study, all six SNPs within the NKAPL and PGBD1 genes displayed an association with schizophrenia, but neither of the two SNPs in the ZKSCAN4 gene showed an association [62].

Furthermore, study evidence was found that genetic variants of the RELA gene are associated with the risk for schizophrenia. The v-rel avian reticuloendotheliosis viral oncogene homolog A (RELA) gene encodes the major subunit of the NF-kB protein complex, are abundantly expressed in neurons and glia [68]. The NFKB3 located on chromosome 11q13 showed a suggestive linkage to schizophrenia in a family-based linkage disequilibrium analysis in a Japanese population [69].

A GWAS study in Caucasian population showed significant association with schizophrenia were in a region of LD on chromosome 6p22.1, including several immunity related genes other than the RELA gene [69]. However, the biological significance of this gene in susceptibility for schizophrenia might not be large, because $22 \%$ of the patients with schizophrenia have homozygous of risk allele in SNP4, but 16\% of the controls also are homozygous of risk allele in SNP4. At the same time, the association between the RELA gene and schizophrenia might explain, at least in part, the relation between immune system and schizophrenia [70].

The results not only provide further evidence that schizophrenia is a complex disease involving immune systems [16] [58] [59], but also indicate that the resultant genes identified in the modules are expressed in brain tissues, suggesting these genes may play important roles in brain function [8].

\subsection{TCF4 and ZNF804A Association with microRNA}

The most recent GWAS of schizophrenia identified five new association loci and the strongest new finding was with $\operatorname{rs} 1625579(\mathrm{P}=1.6 \times 10-11)$ within an intron of a putative primary transcript for miRNA137, a known regulator of neuronal development [66] [71]. In addition, the TCF4 gene is target of several microRNAs, including the mir-137, which was implicated in SCZ etiology in GWAS studies [72]. In particular, the SCZ-associated rs1625579 SNP in miR-137 was correlated with the decreased expression of this microRNA in the dorsolateral prefrontal cortex and a consequent increase in TCF4 levels [73] [74]. In another analysis was suggested that $Z N F 804 A$ may link miRNA137 to 
the specific molecular pathways or cellular processes implicated in schizophrenia, and experimental evidences were warranted to confirm the direct action between miRNA137 and $Z N F 804 A$. It has been suggested that the dysregulation of some miRNAs could be involved in the pathophysiology of schizophrenia [71] [75] [76].

\subsection{Neuregulin Gene}

Two critical neurodevelopmental genes that have been linked to schizophrenia susceptibility are neuregulin 1 [77] (NRG1,8p22-p11) [19] and its receptor ERBB4 [77] [78] [79] [80].

It is possible that elevated levels of cleaved ECTO-ERBB4 may neutralise the membrane-bound $C R D-N R G 1$ (encoded by $N R G 1$-Type III synthesized by pyramidal neurons) resulting in reduced cross-talk between $N R G 1$ and $E R B B 4$. Importantly, $N R G 1-E R B B 4$ signaling has been shown to be important for the development of inhibitory circuits, and a reduction in NRG1-ERBB4 cross-talk does result in reduced molecular markers of inhibitory synapses [81] [82].

Alternatively, elevated levels of cleaved ECTO-ERBB4 may result in increased $N R G 1$ backward-signaling, and in turn, altered gene expression in schizophrenia. This observation is consistent with their previous findings linking the schizophrenia-associated HAPICE risk haplotype [80] with increased NRG1-Type III mRNA expression [83], and their earlier observations of increased cytoplasmic NRG1-ICD in schizophrenia [77] [84].

Moreover, Chen et al. [85] found strong evidence of association between "delusion factor" and SNPs of Neuregulin3 (NRG3) on chromosome 10q22-q23, a region identified in their previous genome-wide linkage analysis of schizophrenia [86].

\subsection{Chromossome $13 \mathrm{q} 32$ and 11p15.4}

Blouin et al. [87] reported a non-parametric linkage (NPL) analysis providing significant evidence for an SSL on chromosome 13q32 (NPL score $=4.18 ; \mathrm{p}=$ 0.000002 ), and suggestive evidence for another SSL on chromosome 8p21-22 $(\mathrm{NPL}=3.46 ; \mathrm{p}=0.0001)$. In the study was founded suggestive evidence for linkage on chromosomal regions 13q32 and 11p15.4 under the criteria of Lander and Kruglyak [88].

Brzustowicz et al. [89] analyzed 21 Canadian families with schizophrenia and found genome-wide significant LOD scores on 13q. Brzustowicz et al. [90], using the same dataset and multipoint analysis and found a maximum LOD score of 3.81 with an empirical $\mathrm{p}=0.02$ under a recessive-broad model of schizophrenia at D13S793, with an estimated $65 \%$ of families linked to this region.

Some more recent studies found evidence for a role of chromosome 11p15.4 in bipolar disorder [91], autism [92] and attention deficit hyperactivity disorder [93]. This relative lack of previous evidence for chromosome 11p15 contrasted with the strong previous findings available for 13q32 [23].

Thus, although they should not disregard the linkage with 11p15.4, their pri- 
mary finding is an additional evidence for a potential role for $13 \mathrm{q} 32$ region in a small Brazilian sample of families with early onset schizophrenia affected individuals. The allele-sharing model tested is compatible with allelic homogeneity within the families [23].

\subsection{Genes Involved in Glutamatergic Pathway}

Hypoglutamatergic hypothesis, which postulates disturbances in the glutamate neurotransmitter pathway, is one of the neurochemical hypotheses of schizophrenia pathogenesis, which in recent times, has attracted attention from researchers [94].

There is considerable evidence suggesting the involvement of ionotrophic glutamate receptors in SCZ [95] [96].

Changes in affinity of glutamate receptors, transcription of their genes, and expression of their subunits in the prefrontal cortex, hippocampus, and thalamus have been revealed in schizophrenics in post mortem studies [97].

In a study, was examined the association of the protein tyrosine phosphatase non-receptor 5 ( $P T P N 5)$ gene, which encodes for Striatal-enriched protein tyrosine phosphatase (STEP), with both schizophrenia and cognitive. The variants of protein tyrosine phosphatase non-receptor 5 (PTPN5), the STEP encoding gene involved in glutamate receptor trafficking, are associated with both the diagnosis of SCZ and with neurocognitive function in general [98].

The GRIN2B gene encoding the subunit NR2B NMDA glutamate receptor and its association with schizophrenia was studied in Russians and Tartars, yielding positive results [94].

In genetic studies, previously, they have found some evidence which is components of the glutamate system, namely the GRIN2B gene [99].

Another gene involved in the modulation of glutamatergic transmission is the dystrobrevin-binding protein 1 ( $D T N B P 1)$ gene, known to the dysbindin gene is located in chromosome 6p22.3 [100] [101] [102].

In fact, in primary cortical neuronal culture, dysbindin appears to influence exocytotic glutamate release via upregulation of molecules in presynaptic machinery [100] [102].

The GRIA2 ionotropic glutamate receptor gene consists of 16 exons and 15 introns and codes for the GluR2 subunit of the $A M P A$ glutamate receptor [5].

The GRIK1 gene (glutamate receptor ionotropic kainate-1) is located on human chromosome 21q22 with 18 exons [103] [104].

The GRIK2 gene codes for subunit 2 of the kainite glutamate receptor and includes 17 exons. The gene is expressed in the granular layer of the cerebellum, the dentate gyrus of the hippocampus, and the neocortex [5].

The results point to potential involvement of GRIK1 in Caucasian schizophrenia patients [104].

It is also known that GRIK2 (6q1621) and GRIA2 (4q3233) are in schizophrenia linked chromosome regions [5] [105] [106].

From a functional perspective, FXYD6 is a member of the FXYD protein fam- 
ily. All members of this family have been shown to modulate Na, K-ATPase and have long-term physiological importance in maintaining cation homeostasis [107].

Interestingly, $\mathrm{Na}, \mathrm{K}-\mathrm{ATPases}$ and glutamate (the major excitatory neurotransmitter in the mammalian brain) are part of the same macromolecular complex and operate as a functional unit to regulate glutamatergic neurotransmission [2] [108].

Zhong et al. [2] reported that the G allele of rs11544201, located in the third exon of FXYD6, is a compelling risk factor for schizophrenia in Han Chinese.

\subsection{Schizophrenia and Brain Structure}

Cognitive deficits are a core feature in SCZ [109], and brain structural changes such as reduced hippocampal and cortical volume [110], the extracellular matrix (ECM) abnormalities [111], as well as reduced cortical thickness [112] have been reported in SCZ patients.

The neural ECM has a specific molecular composition, with chondroitin sulfate proteoglycans (CSPGs) organised as perineuronal nets (PNNs), enveloping neuronal soma and dendrites [111].

The Human Natural Killer-1 (HNK-1) carbohydrate is among the most characteristic glycoepitopes in the nervous system, involved in neural crest cell migration, neurite outgrowth, neuronal cell adhesion, and synaptic plasticity [113] [114]. Kähler et al. [13] suggest that effects on biosynthesis of the neuronal epitope $H N K-1$, through common variation in $B 3 G A T 2$, might decrease cortical surface area and thus increase the risk of SCZ.

ADAMTSL3 is a member of the ADAMTS superfamily of proteins, encompassing the 19 human $A D A M T S$ metalloproteases and the seven non-proteolytic $A D A M T S$-like proteins [6].

ADAMTSL3 itself has been shown to be an important ECM component [115].

Considering the known biology of other superfamily members in the neural ECM, we propose that ADAMTSL3 could plausibly be involved in the PNN abnormalities seen in schizophrenia [111].

Meanwhile, the dysbindin (dystrobrevin-binding protein 1) gene has been indicated as one of the most important schizophrenia susceptibility genes. The dystrobrevin-binding protein 1 ( $D T N B P 1)$ gene, known as the dysbindin gene, is located in chromosome $6 \mathrm{p} 22.3$, encodes 40 - $50 \mathrm{kDa}$ protein, which is widely expressed in neurons of the human brain, and plays a significant role in modulating glutamatergic neurotransmission [100] [101]. Recently, the C-A-T haplotype (derived from SNPs rs2619539, rs3213207 and rs2619538) reported by Williams et al. [116] has shown a strong association with schizophrenia, reduced dysbindin mRNA expression in human post-mortem analysis of homogenized human brain [117], poorer cognitive performance in working memory [118] and reduced gray matter volume in the prefrontal cortex in patients with schizophrenia [102] [119]. 


\subsection{Negative Results}

In the study of genes that give the scenario susceptibility to schizophrenia, some genes were tested, and there were no satisfactory results, like $P E A 15$ genes, ENTPD4, Genes GAS2L1 [120] and COMT[12].

The PEA15 gene is located at 1q21.1, the gene is ENTPD4 on $8 \mathrm{p} 21.3$ and GAS2L1 gene is in 22q12. These three genes are homologous [120]. The COMT gene is located at $22 \mathrm{q} 11.2$, which is a region that has been implicated in linkage areas of SCZ [12] [121].

This single-nucleotide polymorphism (SNP) has been widely studied for its connection with SCZ susceptibility, but with conflicting results [120]. Saito et al. [120] suggests that PEA15 and GAS2L1 do not play an important role in susceptibility to schizophrenia in the Japanese population. Saito et al. [120] left ENTPD4 out of further analysis beyond the screening scan sample subset, since high $\mathrm{P}$ values for allelic frequencies suggest that this gene is also unlikely to be related to schizophrenia.

Other genes have also been investigated in schizophrenia with predominantly negative results are $Z I C 2, S L C 15 A 1$, and FGF14 [23] (Figure 6).

However, further research on these genes which are located on schizophrenia susceptibility loci, using different SNP's and a large sample set will be required [120].

\section{Strengths}

This study involves a search for genetic risk markers for Schizophrenia; Besides, a meta-analysis of studies was carried out, allowing a better understanding and a more precise analysis of the relation of genetic changes and Schizophrenia onset. Most of the analyzed studies have shown an association, in a greater or lesser level, with Schizophrenia. Moreover, there is a need for more meta-analyses of studies on this topic in the literature.

\section{Limitations}

Trough this analysis it was not possible to determine what kinds of genetic

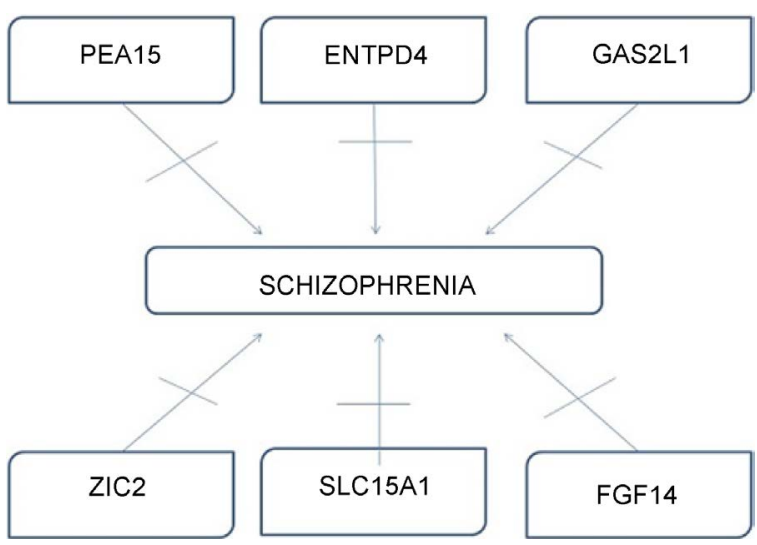

Figure 6. Genes that were tested negative for susceptibility to schizophrenia. 
changes presented a higher risk to the schizophrenia development. Besides, the sample size was restricted due to the inclusion criteria.

\section{Conclusion}

This study shows numerous genetic targets have been identified related to susceptibility to schizophrenia. Great steps have been taken on this theme, but there is still a real need for more detailed studies like ours, addressing this same topic with a larger sample, in view of that the existence of genetic markers and mutations for SCZ is still controversial. Thus, gathering these markers and mutations already set to develop studies with this approach will enable the prevention, diagnosis and more targeted treatment for patients with schizophrenia, improving their quality of life.

\section{Role of Funding Source}

We have no funding source.

\section{Conflict of Interest}

The authors declare no conflict of interest.

\section{References}

[1] O’Donovan, M.C., Craddock, N., Norton, N., Williams, H., Peirce, T., Moskvina, V., Nikolov, I., Hamshere, M., Carroll, L., Georgieva, L., Dwyer, S., Holmans, P., Marchini, J.L., Spencer, C.C.A., Howie, B., Leung, H., Hartmann, A.M., Moller, H., Morris, D.W., Shi, Y., Feng, G., Hoffmann, P., Propping, P., Vasilescu, C., Maier, W., Rietschel, M., Zammit, S., Schumacher, J., Quinn, E.M., Schulze, T.G., Williams, N.M., Giegling, I., Iwata, N., Ikeda, M., Darvasi, A., Shifman, S., He, L., Duan, J., Sanders, A.R., Levinson, D.F., Gejman, P.V., Cichon, S., Nothen, M.M., Gill, M., Corvin, A., Rujescu, D., Kirov, G. and Owen, M.J. (2008) Identification of Loci Associated with Schizophrenia by Genome-Wide Association and Follow-Up. Nature Genetics, 40, 1053-1055. https://doi.org/10.1038/ng.201

[2] Zhong, N., Zhang, R., Qiu, C., Yan, H., Valenzuela, R.K., Zhang, H., Kang, W., Lu, S., Guo, T. and Ma, J. (2011) A Novel Replicated Association between FXYD6 Gene and Schizophrenia. Biochemical and Biophysical Research Communications, 405, 118-121.

[3] Owen, M.J., Williams, H.J. and O’Donovan, M.C. (2009) Schizophrenia Genetics: Advancing on Two Fronts. Current Opinion in Genetics and Development, 19, $266-$ 270. https://doi.org/10.1016/j.gde.2009.02.008

[4] Arab, A.H. and Elhawary, N.A. (2015) Association between ANKK1 (rs1800497) and LTA (rs909253) Genetic Variants and Risk of Schizophrenia. BioMed Research International, 2015, Article ID: 821827.

[5] Gareeva, A.E. and Khusnutdinova, E.K. (2014) Polymorphism of the Glutamate Receptor Genes and Risk of Paranoid Schizophrenia in Russians and Tatars from the Republic of Bashkortostan. Molecular Biology, 48, 671-680. https://doi.org/10.1134/s0026893314050033

[6] Dow, D.J., Huxley-Jones, J., Hall, J.M., Francks, C., Maycox, P.R., Kew, J.N.C., Gloger, I.S., Mehta, N.A.L., Kelly, F.M., Muglia, P., Breen, G., Jugurnauth, S., Pederoso, I., St. Clair, D., Rujescu, D. and Barnes, M.R. (2011) ADAMTSL3 as a Candi- 
date Gene for Schizophrenia: Gene Sequencing and Ultra-High Density Association Analysis by Imputation. Schizophrenia Research, 127, 28-34.

https://doi.org/10.1016/j.schres.2010.12.009

[7] Sun, Y., Zhang, J., Yuan, Y., Yu, X., Shen, Y. and Xu, Q. (2012) Study of a Possible Role of the Monoamine Oxidase A $(M A O A)$ Gene in Paranoid Schizophrenia Among a Chinese Population. American Journal of Medical Genetics Part B: Neuropsychiatric Genetics, 159B, 104-111. https://doi.org/10.1002/ajmg.b.32009

[8] Yu, H., Bi, W., Liu, C., Zhao, Y., Zhang, J.F., Zhang, D. and Yue, W. (2014) ProteinInteraction-Network-Based Analysis for Genome-Wide Association Analysis of Schizophrenia in Han Chinese Population. Journal of Psychiatric Research, 50, 73 78. https://doi.org/10.1016/j.jpsychires.2013.11.014

[9] Cohen, J.D. and Servan-Schreiber, A. (1993) A Theory of Dopamine Function and Its Role in Cognitive Deficits in Schizophrenia. Schizophrenia Bulletin, 19, 85-104. https://doi.org/10.1093/schbul/19.1.85

[10] Carlsson, A., Hansson, L.O., Waters, N. and Carlsson, M.L. (1997) Neurotransmitter Aberrations in Schizophrenia: New Perspectives and Therapeutic Implications. Life Sciences, 61, 75-94.

[11] Dai, D., Cheng, J., Zhou, K., Lv, Y., Zhuang, Q., Zheng, R., Zhang, K., Jiang, D., Gao, S. and Duan, S. (2014) Significant Association between DRD3 Gene Body Methylation. Psychiatry Research, 220, 772-777. https://doi.org/10.1016/j.psychres.2014.08.032

[12] Zhang, F., Liu, C., Chen, Y., Wang, L., Lu, T., Yan, H., Ruan, Y., Yue, W. and Zhang, D. (2012) No Association of Catechol-O-Methyltransferase Polymorphisms with Schizophrenia in the Han Chinese Population. Genetic Testing and Molecular Biomarkers, 16, 1138-1141. https://doi.org/10.1089/gtmb.2012.0061

[13] Kähler, A.K., Djurovic, S., Rimol, L.M., Brown, A.A., Jönsson, E.G., Hansen, T., Gústafsson, Ó., Hall, H., Giegling, I., Muglia, P., Cichon, S., Rietschel, M., Pietilä, O.P.H., Peltonen, L., Bramon, E., Collier, D., Clair, D.S., Sigurdsson, E., Petursson, H., Rujescu, D., Melle, I., Steen, V.M., Dale, A.M., Matthew, R.T., Agartz, I. and Andreassen, O.A. (2011) Candidate Gene Analysis of the Human Natural Killer-1 Carbohydrate Pathway and Perineuronal Nets in Schizophrenia: B3GAT2 Is Associated with Disease Risk and Cortical Surface Area. Biological Psychiatry, 69, 90-96. https://doi.org/10.1016/j.biopsych.2010.07.035

[14] Muller, N., Micheal, R., Manfred, A. and Markus, J. (1999) The Role of Immune Function in Schizophrenia: An Overview. European Archives of Psychiatry and Clinical Neuroscience, 249, S62-S68. https://doi.org/10.1007/PL00014187

[15] Naz, M., Riaz, M. and Saleem, M. (2011) Potential Role of Neuregulin 1 and TNF-Alpha (-308) Polymorphism in Schizophrenia Patients Visiting Hospitals in Lahore, Pakistan. Molecular Biology Reports, 38, 4709-4714. https://doi.org/10.1007/s11033-010-0606-0

[16] International Schizophrenia Consortium (2009) Common Polygenic Variation Contributes to Risk of Schizophrenia and Bipolar Disorder. Nature, 460, 748-752.

[17] The Schizophrenia Psychiatric Genome-Wide Association Study (GWAS) Consortium (2014) Biological Insights from 108 Schizophrenia-Associated Genetic Loci. Nature, 511, 421-427.

[18] Moselhy, H., Eapen, V., Akawi, N.A., Younis, A., Salih, B., Othman, A.R., Yousef, S., Clarke, R.A. and Ali, B. (2015) Secondary Association of PDLIM5 with Paranoid Schizophrenia in Emirati Patients. Meta Gene, 5, 135-139.

[19] Kang, C., Zhou, L., Liu, H. and Yang, J. (2011) Association Study of the Frizzled 3 Gene with Chinese Va Schizophrenia. Neuroscience Letters, 505, 196-199. 
[20] Sullivan, P.F. (2005) The Genetics of Schizophrenia. PLoS Medicine, 2, e212. https://doi.org/10.1371/journal.pmed.0020212

[21] Sullivan, P., Kendler, K. and Neale, M. (2003) Schizophrenia as a complex Trait: Evidence from a Meta-Analysis of Twin Studies. Archives of General Psychiatry, 60, 1187-1192. https://doi.org/10.1001/archpsyc.60.12.1187

[22] Cardno, A., Marshall, E., Coid, B., Macdonald, A. and Ribchester, T. (1999) Heritability Estimates for Psychotic Disorders: The Maudsley Twin Psychosis Series. Archives of General Psychiatry, 56, 162-168. https://doi.org/10.1001/archpsyc.56.2.162

[23] Gadelha, A., Ota, V.K., Cano, J.P., Melaragno, M.I., Smith, M.A.C., de Jesus Mari, J., Bressan, R.A., Belangero, S.I. and Breen, G. (2012) Linkage Replication for Chromosomal Region 13q32 in Schizophrenia: Evidence from a Brazilian Pilot Study on Early Onset Schizophrenia Families. PLoS ONE, 7, e52262.

https://doi.org/10.1371/journal.pone.0052262

[24] Jarskog, L.F., Glantz, L.A., Gilmore, J.H. and Lieberman, J.A. (2005) Apoptotic Mechanisms in the Pathophysiology of Schizophrenia. Progress in Neuro-Psychopharmacology and Biological Psychiatry, 29, 846-858.

[25] Martin, M., Leffler, J. and Blom, A.M. (2012) Annexin A2 and A5 Serve as New Ligands for C1Q on Apoptotic Cells. The Journal of Biological Chemistry, 287, 3373333744. https://doi.org/10.1074/jbc.M112.341339

[26] Schoknecht, K. and Shalev, H. (2012) Blood-Brain Barrier Dysfunction in Brain Diseases: Clinical Experience. Epilepsia, 53, 7-13. https://doi.org/10.1111/j.1528-1167.2012.03697.x

[27] Boyajyan, A.S., Chavushyan, A.S., Zakharyan, R.V. and Mkrtchyan, G.M. (2013) Markers of Apoptotic Dysfunctions in Schizophrenia. Molecular Biology, 47, 587591. https://doi.org/10.1134/s002689331304002x

[28] Lin, T., Kim, G. and Chen, J. (2003) Differential Regulation of Thrombospondin-1 and Thrombospondin-2 after Focal Cerebral Ischemia/Reperfusion. Stroke, 34, 177-186. https://doi.org/10.1161/01.STR.0000047100.84604.BA

[29] Tran, M. and Neary, J. (2006) Purinergic Signaling Induces Thrombospondin-1 Expression in Astrocytes. Proceedings of the National Academy of Sciences of the United States of America, 103, 9321-9326. https://doi.org/10.1073/pnas.0603146103

[30] Yonezawa, T., Hattori, S., Inagaki, J., Kurosaki, M., Takigawa, T., Hirohata, S., Miyoshi, T. and Ninomiya, Y. (2010) Type IV Collagen Induces Expression of Thrombospondin-1 That Is Mediated by Integrin Alpha1Beta1 in Astrocytes. Glia, 58, 755-767.

[31] Herrick, S., Evers, D.M., Lee, J.Y., Udagawa, N. and Pak, D.T. (2010) Postsynaptic PDLIM5/Enigma Homolog Binds SPAR and Causes Dendritic Spine Shrinkage. Molecular and Cellular Neuroscience, 43, 188-200.

[32] Bourne, J.N. and Harris, K.M. (2008) Balancing Structure and Function at Hippocampal Dendritic Spines. Annual Review of Neuroscience, 31, 47-67. https://doi.org/10.1146/annurev.neuro.31.060407.125646

[33] Stober, G., Saar, K. and Ruschendorf, F. (2000) Splitting Schizophrenia: Periodic Catatonia-Susceptibility Locus on Chromosome 15q15. The American Journal of Human Genetics, 67, 1201-1207.

[34] Kury, S., Rubie, C., Moisan, J. and Stober, G. (2003) Mutation Analysis of the Zinc Transporter Gene SLC30A4 Reveals no Association with Periodic Catatonia on Chromosome 15q15. Journal of Neural Transmission, 110, 1329-1332. https://doi.org/10.1007/s00702-003-0060-4

[35] Moon, H., Yim, S., Lee, W., et al. (2006) Identification of DNA Copy-Number Ab- 
errations by Array-Comparative Genomic Hybridization in Patients with Schizophrenia. Biochemical and Biophysical Research Communications, 344, 531-539.

[36] Clarke, R.A. and Eapen, V. (2014) Balance within the Neurexin Trans-Synaptic Connexus Stabilizes Behavioral Control. Frontiers in Human Neuroscience, 8, e52. https://doi.org/10.3389/fnhum.2014.00052

[37] Clarke, R.A., Lee, S. and Eapen, V. (2012) Pathogenetic Model for Tourette Syndrome Delineates Overlap with Related Neurodevelopmental Disorders Including Autism. Translational Psychiatry, 2, e158. https://doi.org/10.1038/tp.2012.75

[38] Sharma, R.P., Grayson, D.R. and Gavin, D.P. (2008) Histone Deactylase 1 Expression Is Increased in the Prefrontal Cortex of Schizophrenia Subjects: Analysis of the National Brain Databank Microarray Collection. Schizphrena Research, 98, 111 117. https://doi.org/10.1016/j.schres.2007.09.020

[39] Akbarian, S., Ruehl, M.G., Bliven, E., Luiz, L.A., Peranelli, A.C., Baker, S.P., Roberts, R.C., Bunney Jr., W.E., Conley, R.C. and Jones, E.G. (2005) Chromatin Alterations Associated with Down-Regulated Metabolic Gene Expression in the Prefrontal Cortex of Subjects with Schizophrenia. Archives of General Psychiatry, 62, 829-840. https://doi.org/10.1001/archpsyc.62.8.829

[40] Joshi, P., Greco, T.M., Guise, A.J., Luo, Y., Yu, F., Nesvizhskii, A.I. and Cristea, I.M. (2013) The Functional Interactome Landscape of the Human Histone Deacetylase Family. Molecular Systems Biology, 9, 672. https://doi.org/10.1038/msb.2013.26

[41] Kebir, O., Chaumette, B., Fatjó-Vilas, M., Ambalavanan, A., Ramoz, N., Xiong, L., Mouaffak, F., Millet, B., Jaafari, N., DeLisi, L.E., Levinson, D., Joober, R., Fañanás, L., Rouleau, G., Dubertret, C. and Krebs, M.O. (2014) Family-Based Association Study of Common Variants, Rare Mutation Study and Epistatic Interaction Detection in HDAC Genes in Schizophrenia. Schizophrenia Research, 160, 97-103. https://doi.org/10.1016/j.schres.2014.09.029

[42] Morris, J., Kandpal, G. and Ma, L. (2003) DISC1 (Disrupted-In-Schizophrenia 1) Is a Centrosome-Associated Protein That Interacts with MAP1A, MIPT3, ATF4/5 and NUDEL: Regulation and Loss of Interaction with Mutation. Human Molecular Genetics, 12, 1591-1608. https://doi.org/10.1093/hmg/ddg162

[43] Ozeki, Y., Tomoda, T. and Kleiderlein, J. (2003) Disrupted-in-Schizophrenia-1 (DISC-1): Mutant Truncation Prevents Binding to NudE-Like (NUDEL) and Inhibits Neurite Outgrowth. Proceedings of the National Academy of Sciences of the United States of America, 100, 289-294. https://doi.org/10.1073/pnas.0136913100

[44] Cannon, T., Hennah, W. and van Erp, T. (2005) Association of DISC1/TRAX Haplotypes with Schizophrenia, Reduced Prefrontal Gray Matter, and Impaired Shortand Long-Term Memory. Archives of General Psychiatry, 62, 1205-1213. https://doi.org/10.1001/archpsyc.62.11.1205

[45] Cao, F., Zhang, H., Feng, J., Gao, C. and Li, S. (2013) Association Study of Three Microsatellite Polymorphisms Located in Introns 1, 8, and 9 of DISC1 with Schizophrenia in the Chinese Han Population. Genetic Testing and Molecular Biomarkers, 17, 407-411. https://doi.org/10.1089/gtmb.2012.0438

[46] Norlelawati, A.T., Kartini, A., Norsidah, K., Ramli, M., Tariq, A.R. and Wan Rohani, W.T. (2013) Disrupted-in-Schizophrenia-1 SNPs and Susceptibility to Schizophrenia: Evidence from Malaysia. Psychiatry Investigation, 12, 103-111. https://doi.org/10.4306/pi.2015.12.1.103

[47] Yamada, K., Iwayama, Y., Toyota, T., Ohnishi, T., Ohba, H., Maekawa, M. and Yoshikawa, T. (2012) Association Study of the KCN/3 Gene as a Susceptibility Candidate for Schizophrenia in the Chinese Population. Human Genetics, 131, 443-451. https://doi.org/10.1007/s00439-011-1089-3 
[48] Okahisa, Y., Kodama, M., Takaki, M., et al. (2011) Association between the Regulator of G-Protein Signaling 9 Gene and Patients with Methamphetamine Use Disorder and Schizophrenia. Current Neuropharmacology, 9, 190-194.

[49] Réthelyi, J.M., Bakker, S.C. and Polgár, P. (2010) Association Study of NRG1, DTNBP1, RGS4, G72/G30, and PIP5K2A with Schizophrenia and Symptom Severity in a Hungarian Sample. American Journal of Medical Genetics Part B: Neuropsychiatric Genetics, 153, 792-801.

[50] De Blasi, A., Conn, P.J., Pin, J.P. and Nicoletti, F. (2001) Molecular Determinants of Metabotropic Glutamate Receptor Signaling. Trends in Pharmacological Sciences, 22, 114-120. https://doi.org/10.1016/S0165-6147(00)01635-7

[51] De Vries, L., Zheng, B., Fischer, T., Elenko, E. and Farquhar, M.G. (2000) The Regulator of G Protein Signaling Family. Annual Review of Pharmacology and Toxicology, 40, 235-271.

[52] Gareeva, A.E., Zakirov, D.F., Valinurov, R.G. and Khusnutdinova, E.K. (2013) Polymorphism of RGS2 Gene as Genetic Marker of Schizophrenia Risk and Pharmacogenetic Markers of the Efficiency of Typical Neuroleptics. Molecular Biology, 47, 814-820. https://doi.org/10.1134/S0026893313060046

[53] Talkowski, M.E., Mansour, H., Chowdari, K.V., Wood, J., Butler, A., Varma, P.G., Prasad, S., Semwal, P., Bhatia, T., Deshpande, S., Devlin, B., Thelma, B.K. and Nimgaonkar, V.L. (2006) Novel, Replicated Associations between Dopamine D3 Receptor Gene Polymorphisms and Schizophrenia in Two Independent Samples. Biological Psychiatry, 60, 570-577. https://doi.org/10.1016/j.biopsych.2006.04.012

[54] Meltzer, H.Y. (1989) Clinical Studies on the Mechanism of Action of Clozapine: The Dopamine-Serotonin Hypothesis of Schizophrenia. Psychopharmacology, 99, S18-S27.

[55] Mota, N.R., Araujo-Jnr, E.V., Paixão-Côrtes, V.R., Bortolini, M.C. and Bau, C.H.D. (2012) Linking Dopamine Neurotransmission and Neurogenesis: The Evolutionary History of the NTAD (NCAM1-TTC12-ANKK1-DRD2) Gene Cluster. Genetics and Molecular Biology, 35, 912-918. https://doi.org/10.1590/S1415-47572012000600004

[56] Doehring, A., Hentig, N.V. and Graff, J. (2009) Genetic Variants Altering DopamineD2 Receptor Expression or Function Modulate the Risk of Opiate Addiction and the Dosage Requirements of Methadone Substitution. Pharmacogenetics and Genomics, 19, 407-414.

[57] Jonsson, E.G., Nothen, M.M. and Neidt, H. (1999) Association between a Promoter Polymorphism in the Dopamine D2 Receptor Gene and Schizophrenia. Schizophrenia Research, 40, 31-36. https://doi.org/10.1016/S0920-9964(99)00033-X

[58] Shi, J., Levinson, D., Duan, J., Sanders, A. and Zheng, Y. (2009) Common Variants on Chromosome 6p22.1 Are Associated with Schizophrenia. Nature, 460, 753-757. https://doi.org/10.1038/nature08192

[59] Stefansson, H., Ophoff, R., Steinberg, S., Andreassen, O. and Cichon, S. (2009) Common Variants Conferring Risk of Schizophrenia. Nature, 460, 744-747. https://doi.org/10.1038/nature08186

[60] Ikeda, M., Aleksic, B., Kinoshita, Y., Okochi, T. and Kawashima, K. (2011) Genome-Wide Association Study of Schizophrenia in a Japanese Population. Biological Psychiatry, 69, 472-478. https://doi.org/10.1016/j.biopsych.2010.07.010

[61] Yue, W., Wang, H., Sun, L., Tang, F. and Liu, Z. (2011) Genome-Wide Association Study Identifies a Susceptibility Locus for Schizophrenia in Han Chinese at 11p11.2. Nature Genetics, 43, 1228-1231. https://doi.org/10.1038/ng.979 
[62] Zhang, Y., Lu, T., Yan, H., Ruan, Y., Wang, L., Zhang, D., Yue, W. and Lu, L. (2013) Replication of Association between Schizophrenia and Chromosome 6p21-6p22.1 Polymorphisms in Chinese Han Population. PLoS ONE, 8, e56732. https://doi.org/10.1371/journal.pone.0056732

[63] Horton, R., Wilming, L., Rand, V., Lovering, R. and Bruford, E. (2004) Gene Map of the Extended Human MHC. Nature Reviews Genetics, 5, 889-899. https://doi.org/10.1038/nrg1489

[64] Shirts, B., Kim, J., Reich, S., Dickerson, F. and Yolken, R. (2007) Polymorphisms in $M I C B$ Are Associated with Human Herpes Virus Seropositivity and Schizophrenia Risk. Schizphrena Research, 94, 342-353. https://doi.org/10.1016/j.schres.2007.04.021

[65] Singh, B., Bera, N., De, S., Nayak, C. and Chaudhuri, T. (2011) Study of HLA Class I gene in Indian Schizophrenic Patients of Siliguri, West Benga. Psychiatry Research, 189, 215-219. https://doi.org/10.1016/j.psychres.2011.03.010

[66] Ripke, S., Sanders, A., Kendler, K., Levinson, D., Sklar, P., Holmans, P., Lin, D.Y., Duan, J., Ophoff, R.A., et al. (2011) Genome-Wide Association Study Identifies Five New Schizophrenia Loci. Nature Genetics, 43, 969-976. https://doi.org/10.1038/ng.940

[67] Steinberg, S., de Jong, S., Andreassen, O., Werge, T., Borglum, A., Mors, O., et al. (2011) Common Variants at VRK2 and TCF4 Conferring Risk of Schizophrenia. Human Molecular Genetics, 20, 4076-4081. https://doi.org/10.1093/hmg/ddr325

[68] Kaltschmidt, B. and Kaltschmidt, C. (2009) NF-kappaB in the Nervous System. Cold Spring Harbor Perspectives in Biology, 1, a001271.

[69] Yamada, K., Iwayama-Shigeno, Y., Yoshida, Y., Toyota, T., Itokawa, M., Hattori, E., et al. (2004) Family-Based Association Study of Schizophrenia with 444 Markers and Analysis of a New Susceptibility Locus Mapped to 11q13.3. American Journal of Medical Genetics Part B: Neuropsychiatric Genetics, 127B, 11-19. https://doi.org/10.1002/ajmg.b.20166

[70] Hashimoto, R., Ohi, K., Yasuda, Y., Fukumoto, M., Yamamori, H., Takahashi, H., Iwase, M., Okochi, T., Kazui, H., Saitoh, O., Tatsumi, M., Iwata, N., Ozaki, N., Kamijima, K., Kunugi, H. and Takeda, M. (2011) Variants of the RELA Gene Are Associated with Schizophrenia and Their Startle Responses. Neuropsychopharmacology, 36, 1921-1931. https://doi.org/10.1038/npp.2011.78

[71] Zhang, R., Yan, J.D., Valenzuela, R.K., Lu, S.M., Du, X.Y., Zhong, B., Ren, J., Zhao, S.H., Gao, C.G., Wang, L., Guo, T.W. and Ma, J. (2012) Further Evidence for the Association of Genetic Variants of $Z N F 804 A$ with Schizophrenia and a MetaAnalysis for Genome-Wide Significance Variant rs1344706. Schizophrenia Research, 141, 40-47. https://doi.org/10.1016/j.schres.2012.07.013

[72] Ripke, S., O’Dushlaine, C., Chambert, K., Moran, J., Kahler, A., et al. (2013) Genome-Wide Association Analysis Identifies 13 New Risk Loci for Schizophrenia. Nature Genetics, 45, 1150-1159. https://doi.org/10.1038/ng.2742

[73] Guella, I., Sequeira, A., Rollins, B., Morgan, L., Torri, F., et al. (2013) Analysis of miR-137 Expression and rs1625579 in Dorsolateral Prefrontal Cortex. Psychiatry Research, 47, 1215-1221. https://doi.org/10.1016/j.jpsychires.2013.05.021

[74] Cattane, N., Minelli, A., Milanesi, E., Maj, C., Bignotti, S., Bortolomasi, M., Chiavetto, L.B. and Gennarelli, M. (2015) Altered Gene Expression in Schizophrenia: Findings from Transcriptional Signatures in Fibroblasts and Blood. PLoS ONE, 10, e0116686. https://doi.org/10.1371/journal.pone.0116686

[75] Hansen, T., Olsen, L., Lindow, M., Jakobsen, K.D., Ullum, H., Jonsson, E., Andreassen, O.A., Djurovic, S., Melle, L., Agartz, I., Hall, H., Timm, S., Wang, A.G. 
and Werge, T. (2007) Brain Expressed microRNAs Implicated in Schizophrenia Etiology. PLoS ONE, 2, e873. https://doi.org/10.1371/journal.pone.0000873

[76] Beveridge, N.J. and Cairns, M.J. (2012) MicroRNA Dysregulation in Schizophrenia. Neurobiology of Disease, 46, 263-271. https://doi.org/10.1016/j.nbd.2011.12.029

[77] Joshi, D., Fullerton, J.M. and Weickert, C.S. (2014) Elevated ErbB4 mRNA Is Related to Interneuron Deficit in Prefrontal Cortex in Schizophrenia. Journal of Psychiatric Research, 53, 125-132. https://doi.org/10.1016/j.jpsychires.2014.02.014

[78] Norton, N., Moskvina, V., Morris, D., Bray, N., Zammit, S., Williams, N., et al. (2006) Evidence That Interaction between Neuregulin 1 and Its Receptor erbB4 Increases Susceptibility to Schizophrenia. American Journal of Medical Genetics Part B: Neuropsychiatric Genetics, 141B, 96-101. https://doi.org/10.1002/ajmg.b.30236

[79] Silberberg, G., Darvasi, A., Pinkas-Kramarski, R. and Navon, R. (2006) The Involvement of ErbB4 with Schizophrenia: Association and Expression Studies. American Journal of Medical Genetics Part B: Neuropsychiatric Genetics, 141B, 142-148. https://doi.org/10.1002/ajmg.b.30275

[80] Stefansson, H. (2002) Neuregulin 1 and Susceptibility to Schizophrenia. American Journal of Human Genetics, 71, 877-892. https://doi.org/10.1086/342734

[81] Fazzari, P., Paternain, A., Valiente, M., Pla, R., Lujan, R., Lloyd, K., et al. (2010) Control of Cortical GABA Circuitry Development by Nrg1 and ErbB4 Signalling. Nature, 464, 1376-1380.

[82] Krivosheya, D., Tapia, L., Levinson, J., Huang, K., Kang, Y., Hines, R., et al. (2008) ErbB4-Neuregulin Signaling Modulates Synapse Development and Dendritic Arborization through Distinct Mechanisms. The Journal of Biological Chemistry, 283, 32944-32956. https://doi.org/10.1074/jbc.M800073200

[83] Weickert, C., Tiwari, Y., Schofield, P., Mowry, B. and Fullerton, J. (2012) Schizophrenia-Associated HapICE Haplotype Is Associated with Increased NRG1 Type III Expression and High Nucleotide Diversity. Translational Psychiatry, 2, e104. https://doi.org/10.1038/tp.2012.25

[84] Chong, V., Thompson, M., Beltaifa, S., Webster, M., Law, A. and Weickert, C. (2008) Elevated Neuregulin-1 and ErbB4 Protein in the Prefrontal Cortex of Schizophrenic Patients. Schizophrenia Research, 100, 270-280. https://doi.org/10.1016/j.schres.2007.12.474

[85] Chen, P.L., Avramopoulos, D., Lasseter, V.K., McGrath, J.A., Fallin, M.D., Liang, K.Y., Nestadt, G., Feng, N., Steel, G., Cutting, A.S., Wolyniec, P., Pulver, A.E. and Valle, D. (2009) Fine Mapping on Chromosome 10q22-q23 Implicates Neuregulin 3 in Schizophrenia. American Journal of Human Genetics, 84, 21-34. https://doi.org/10.1016/j.ajhg.2008.12.005

[86] Ryu, S., Won, H.H., Oh, S., Jong-Won, K., Park, T., Cho, E.Y., Cho, Y., Park, D.Y., Lee, Y.S., Kwon, J.S. and Hong, K.S. (2013) Genome-Wide Linkage Scan of Quantitative Traits representing Symptom Dimensions in Multiplex Schizophrenia Families. Psychiatry Research, 210, 756-760. https://doi.org/10.1016/j.psychres.2013.08.015

[87] Blouin, J., Dombroski, B., Nath, S., Lasseter, V., Wolyniec, P., et al. (1998) Schizophrenia Susceptibility Loci on Chromosomes $13 \mathrm{q} 32$ and 8p21. Nature Genetics, 20, 70-73.

[88] Lander, E. and Kruglyak, L. (1995) Genetic Dissection of Complex Traits: Guidelines for Interpreting and Reporting Linkage Results. Nature Genetics, 11, 241-247. https://doi.org/10.1038/ng1195-241

[89] Brzustowicz, L., Honer, W., Chow, E., Little, D. and Hogan, J. (1999) Linkage of 
Familial Schizophrenia to Chromosome 13q32. The American Journal of Human Genetics, 65, 1096-1103. https://doi.org/10.1086/302579

[90] Brzustowicz, L., Hodgkinson, K., Chow, E., Honer, W. and Bassett, A. (2000) Location of a Major Susceptibility Locus for Familial Schizophrenia on Chromosome 1q21-q22. Science, 288, 678-682. https://doi.org/10.1126/science.288.5466.678

[91] Huang, J., Perlis, R., Lee, P., Rush, A., Fava, M., et al. (2010) Cross-Disorder Genomewide Analysis of Schizophrenia, Bipolar Disorder, and Depression. The American Journal of Psychiatry, 167, 1254-1263. https://doi.org/10.1176/appi.ajp.2010.09091335

[92] Liu, X., Paterson, A. and Szatmari, P., The Autism Genome Project Consortium (2008) Genome-Wide Linkage Analyses of Quantitative and Categorical Autism Subphenotypes. Biological Psychiatry, 64, 561-570. https://doi.org/10.1016/j.biopsych.2008.05.023

[93] Gornick, M., Addington, A., Shaw, P., Bobb, A. and Sharp, W. (2007) Association of the Dopamine Receptor D4 (DRD4) Gene 7-Repeat Allele with Children with Attention-Deficit/Hyperactivity Disorder (ADHD): An Update. American Journal of Medical Genetics Part B: Neuropsychiatric Genetics, 144B, 379-382. https://doi.org/10.1002/ajmg.b.30460

[94] Gareeva, A.E., Zakirovb, D.F. and Khusnutdinovaa, E.K. (2013) Association Polymorphic Variants of GRIN2B Gene with Paranoid Schizophrenia and Response to Typical Neuroleptics in Russians and Tatars from Bashkortostan Republic. Russian Journal of Genetics, 49, 962-968. https://doi.org/10.1134/S1022795413080024

[95] Coyle, J.T. (2006) Glutamate and Schizophrenia: Beyond the Dopamine Hypothesis. Cellular and Molecular Neurobiology, 26, 363-382. https://doi.org/10.1007/s10571-006-9062-8

[96] Javitt, D.C. (2010) Glutamatergic Theories of Schizophrenia. The Israel Journal of Psychiatry and Related Sciences, 47, 4-16.

[97] Clinton, S.M. and Meador-Woodruff, J.H. (2004) Thalamic Dysfunction in Schizophrenia: Neurochemical, Neuropathological and in Vivo Imaging Abnormalities. Schizophrenia Research, 69, 237-253. https://doi.org/10.1016/j.schres.2003.09.017

[98] Pelov, I., Teltsh, O., Greenbaum, L., Rigbi, A., Kanyas-Sarner, K., Lerer, B., Lombroso, P. and Kohn, Y. (2012) Involvement of PTPN5, the Gene Encoding the Striatal-Enriched Protein Tyrosine Phosphatase, in Schizophrenia and Cognition. Psychiatric Genetics, 22, 168-176. https://doi.org/10.1097/YPG.0b013e3283518586

[99] Martucci, L., Wong, A.H., De Luca, V., et al. (2006) N-Methyl-D-Aspartate Receptor NR2B Subunit Gene GRIN2B in Schizophrenia and Bipolar Disorder: Polymorphisms and mRNA Levels. Schizophrenia Research, 84, 214-221.

https://doi.org/10.1016/j.schres.2006.02.001

[100] Numakawa, T., Yagasaki, Y., Ishimoto, T., Okada, T., Suzuki, T., Iwata, N., et al. (2004) Evidence of Novel Neuronal Functions of Dysbindin, a Susceptibility Gene for Schizophrenia. Human Molecular Genetics, 13, 2699-2708.

https://doi.org/10.1093/hmg/ddh280

[101] Talbot, K., Cho, D., Ong, W., Benson, M., Han, L., Kazi, H., et al. (2006) Dysbindin-1 Is a Synaptic and Microtubular Protein That Binds Brain Snapin. Human Molecular Genetics, 15, 3041-3054. https://doi.org/10.1093/hmg/ddl246

[102] Cerasa, A., Quattrone, A., Gioia, M.C., Tarantino, P., Annesi, G., Assogna, F., Caltagirone, C., De Luca, V. and Spalletta, G. (2011) Dysbindin C-A-T Haplotype Is Associated with Thicker Medial Orbitofrontal Cortex in Healthy Population. Neurolmage, 55, 508-513. 
[103] Barbon, A. and Barlati, S. (2000) Genomic Organization, Proposed Alternative Splicing Mechanisms, and RNA Editing Structure of GRIK1. Cytogenetics and Cell Genetics, 88, 236-239. https://doi.org/10.1159/000015558

[104] Hirata, Y., Zai, C., Souza, R.P., Lieberman, J.A., Meltzer, H.Y. and Kennedy, J.L. (2012) Association Study of GRIK1 Gene Polymorphisms in Schizophrenia: CaseControl and Family-Based Studies. Human Psychopharmacology, 27, 345-351. https://doi.org/10.1002/hup.2233

[105] Bah, J., Quach, R., Ebstein, P., Segman, R.H., Melke, J., Jamain, S., Rietschel, M., Modai, I., Kanas, K., Karni, O., Lerer, B., Gourion, D., Krebs, M.O., Etain, B., Schürhoff, F., Szöke, A., Leboyer, M. and Bourgeron, T. (2004) Maternal Transmission Disequilibrium of the Glutamate Receptor GRIK2 in Schizophrenia. NeuroReport, 15, 1987-1991.

[106] Ekholm, J.M., Kieseppa, T., Hiekkalinna, T., et al. (2003) Evidence of Susceptibility Loci on 4q32 and 16p12 for Bipolar Disorder. Human Molecular Genetics, 12, 19071915. https://doi.org/10.1093/hmg/ddg199

[107] Geering, K. (2006) FXYD Proteins: New Regulators of Na-K-ATPase. American Journal of Physiology-Renal Physiology, 290, F241-F250. https://doi.org/10.1152/ajprenal.00126.2005

[108] Rose, E.M., Koo, J.C., Antflick, J.E., Ahmed, S.M., Angers, S. and Hampson, D.R. (2009) Glutamate Transporter Coupling to $\mathrm{Na}, \mathrm{K}-\mathrm{ATP}$ ase. Journal of Neuroscienc, 29, 8143-8155. https://doi.org/10.1523/JNEUROSCI.1081-09.2009

[109] Barch, D. (2005) The Cognitive Neuroscience of Schizophrenia. A Annual Review of Clinical Psychology, 1, 321-353. https://doi.org/10.1146/annurev.clinpsy.1.102803.143959

[110] Karlsgodt, K., Sun, D., Jimenez, A., Lutkenhoff, E., Willhite, R., van Erp, T. and Cannon, T. (2008) Developmental Disruptions in Neural Connectivity in the Pathophysiology of Schizophrenia. Development and Psychopathology, 20, 1297-1327. https://doi.org/10.1017/S095457940800062X

[111] Pantazopoulos, H., Woo, T.U., Lim, M.P., Lange, N. and Berretta, S. (2010) Extracellular Matrix-Glial Abnormalities in the Amygdala and Entorhinal Cortex of Subjects Diagnosed with Schizophrenia. Archives of General Psychiatry, 67, 155-166.

[112] Rimol, L., Hartberg, C., Nesvåg, R., Fennema-Notestine, C., Hagler, D.J., Pung, C., et al. (2010) Cortical Thickness and Subcortical Volumes in Schizophrenia and Bipolar Disorder. Biological Psychiatry, 68, 41-50. https://doi.org/10.1016/j.biopsych.2010.03.036

[113] Kleene, R. and Schachner, M. (2004) Glycans and Neural Cell Interactions. Nature Reviews Neuroscience, 5, 195-208. https://doi.org/10.1038/nrn1349

[114] Morita, I., Kizuka, Y., Kakuda, S. and Oka, S. (2008) Expression and Function of the HNK-1 Carbohydrate. The Journal of Biochemistry, 143, 719-724. https://doi.org/10.1093/jb/mvm221

[115] Weedon, M.N., Lango, J., Lindgren, C.M., Wallace, C., Evans, D.M., Mangino, M., Freathy, R.M., Perry, J.R., Stevens, S., Hall, A.S., Samani, N.J., Shields, B., Prokopenko, I., Farrall, M., Dominiczak, A., Diabetes Genetics Initiative, Wellcome Trust Case Control Consortium, Johnson, T., Bergmann, S., Beckmann, J.S., Vollenweider, P., Waterworth, D.M., Mooser, V., Palmer, C.N., Morris, A.D., Ouwehand, W.H., Cambridge GEM Consortium, Zhao, J.H., Li, S., Loos, R.J., Barroso, I., Deloukas, P., Sandhu, M.S., Wheeler, E., Soranzo, N., Inouye, M., Wareham, N.J., Caulfield, M., Munroe, P.B., Hattersley, A.T., McCarthy, M.I., Frayling, T.M., et al. (2008) Genome-Wide Association Analysis Identifies 20 Loci That Influence Adult Height. Nature Genetics, 40, 575-583. 
[116] Williams, N.M., Preece, A., Morris, D.W., Spurlock, G., Bray, N.J., Stephens, M., et al. (2004) Identification in 2 Independent Samples of a Novel Schizophrenia Risk Haplotype of the Dystrobrevin Binding Protein Gene (DTNBP1). Archives of General Psychiatry, 61, 336-344. https://doi.org/10.1001/archpsyc.61.4.336

[117] Bray, N.J., Preece, A., Williams, N.M., Moskvina, V., Buckland, P.R., Owen, M.J. and O’Donovan, M.C. (2005) Haplotypes at the Dystrobrevin Binding Protein 1 (DTNBP1) Gene Locus Mediate Risk for Schizophrenia through Reduced DTNBP1 Expression. Human Molecular Genetics, 14, 1947-1954.

https://doi.org/10.1093/hmg/ddi199

[118] Donohoe, G., Morris, D., Clarke, S., McGhee, K., Schwaiger, S., Nangle, J.M., Garavan, H., Robertson, I.H., Gill, M. and Corvin, A. (2007) Variance in Neurocognitive Performance Is Associated with Dysbindin-1 in Schizophrenia: A Preliminary Study. Neuropsychologia, 45, 454-458.

[119] Donohoe, G., Frodl, T., Morris, D., Spoletini, I., Cannon, D.M., Cherubini, A., Caltagirone, C., Bossù, P., McDonald, C., Gill, M., Corvin, A.P. and Spalletta, G. (2010) Reduced Occipital and Prefrontal Brain Volumes in Dysbindin-Associated Schizophrenia. Neuropsychopharmacology, 35, 368-373. https://doi.org/10.1038/npp.2009.140

[120] Saito, A., Fujikura-Ouchi, Y., Ito, C., Matsuoka, H., Shimoda, K. and Akiyama, K. (2011) An Association Study on Polymorphisms in the PEA15, ENTPD4, and GAS2L1 Genes and Schizophrenia. Psychiatry Research, 185, 9-15. https://doi.org/10.1016/j.psychres.2009.09.018

[121] Lewis, C., Levinson, D., Wise, L., et al. (2003) Genome Scan Meta-Analysis of Schizophrenia and Bipolar Disorder, Part II: Schizophrenia. American Journal of $\mathrm{Hu}$ man Genetics, 73, 34-48. https://doi.org/10.1086/376549

Submit or recommend next manuscript to SCIRP and we will provide best service for you:

Accepting pre-submission inquiries through Email, Facebook, LinkedIn, Twitter, etc. A wide selection of journals (inclusive of 9 subjects, more than 200 journals)

Providing 24-hour high-quality service

User-friendly online submission system

Fair and swift peer-review system

Efficient typesetting and proofreading procedure

Display of the result of downloads and visits, as well as the number of cited articles

Maximum dissemination of your research work

Submit your manuscript at: http://papersubmission.scirp.org/

Or contact health@scirp.org 